\title{
Clinical and Molecular Heterogeneity of RTEL1 Deficiency
}

\author{
Carsten Speckmann 1,2, Sushree Sangita Sahoo ${ }^{1,3}$, Marta Rizzi, ${ }^{2,4}$, Shinsuke Hirabayashi', \\ Axel Karow ${ }^{5}$, Nina Kathrin Serwas ${ }^{6,7}$, Marc Hoemberg ${ }^{8}$, Natalja Damatova, \\ Detlev Schindler ${ }^{9}$, Jean-Baptiste Vannier ${ }^{10}$, Simon J. Boulton ${ }^{10}$, Ulrich Pannicke ${ }^{11}$, \\ Gudrun Göhring ${ }^{12}$, Kathrin Thomay ${ }^{12}$, J. J. Verdu-Amoros ${ }^{13}$, Holger Hauch ${ }^{13}$, \\ Wilhelm Woessmann ${ }^{13}$, Gabriele Escherich ${ }^{14}$, Eckart Laack ${ }^{15}$, Liliana Rindle', \\ Maximilian Seidll,16, Anne Rensing-Ehl' ${ }^{2}$, Ekkehart Lausch ${ }^{1}$, Christine Jandrasits ${ }^{7}$, \\ Brigitte Strahm ${ }^{1}$, Klaus Schwarz ${ }^{11}$, Stephan R. Ehl ${ }^{1,2}$, Charlotte Niemeyer ${ }^{1,17,18}$, \\ Kaan Boztug ${ }^{6,7,19,20+}$ and Marcin W. Wlodarski, ${ }^{17,18 *+}$
}

\section{OPEN ACCESS}

Edited by:

Michael Jordan,

Cincinnati Children's Hospital Medical Center, USA

Reviewed by: Lisa Renee Forbes, Baylor College of Medicine, USA Sharon A. Savage,

National Cancer Institute, USA

*Correspondence:

Marcin W. Wlodarski marcin.wlodarski@ uniklinik-freiburg.de

tThese authors have contributed equally to this work.

Specialty section: This article was submitted to Primary Immunodeficiencies, a section of the journal

Frontiers in Immunology

Received: 31 December 2016 Accepted: 31 March 2017

Published: 01 May 2017

Citation

Speckmann C, Sahoo SS, Rizzi M, Hirabayashi S, Karow A, Serwas NK, Hoemberg M, Damatova N, Schindler D, Vannier J-B, Boulton SJ, Pannicke U, Göhring G, Thomay K, Verdu-Amoros JJ, Hauch $H$, Woessmann W, Escherich G, Laack E, Rindle L, Seidl M,

Rensing-Ehl A, Lausch E, Jandrasits $C$, Strahm B, Schwarz K,

EhI SR, Niemeyer C, Boztug K and Wlodarski MW (2017) Clinical and Molecular Heterogeneity of RTEL1 Deficiency.

Front. Immunol. 8:449. doi: 10.3389/fimmu.2017.00449
${ }^{1}$ Department of Pediatrics and Adolescent Medicine, Division of Pediatric Hematology and Oncology, Medical Centre, Faculty of Medicine, University of Freiburg, Freiburg, Germany, ${ }^{2}$ Center for Chronic Immunodeficiency, Medical Center, Faculty of Medicine, University of Freiburg, Freiburg, Germany, ${ }^{3}$ Spemann Graduate School of Biology and Medicine, University of Freiburg, Freiburg, Germany, ${ }^{4}$ Department of Rheumatology and Clinical Immunology, Medical Centre, Faculty of Medicine, University of Freiburg, Freiburg, Germany, ${ }^{5}$ Department of Paediatrics, Univeristy of Bern, Bern, Switzerland, ${ }^{6}$ Ludwig Boltzmann Institute for Rare and Undiagnosed Diseases, Vienna, Austria, ${ }^{7} \mathrm{CeMM}$ Research Center for Molecular Medicine of the Austrian Academy of Sciences, Vienna, Austria, ${ }^{8}$ Department of Pediatric Hematology and Oncology, Children's Hospital, University of Cologne, Cologne, Germany, ${ }^{9}$ Department of Medical Genetics, Biozentrum, University of Wuerzburg, Wuerzburg, Germany, ${ }^{10}$ Telomere Replication and Stability Group, MRC London Institute of Medical Sciences (LMS), London, UK, ${ }^{11}$ Institute for Transfusion Medicine, Institute for Clinical Transfusion Medicine and Immunogenetics UIm, German Red Cross Blood Service Baden-Wuerttemberg - Hessen, University Ulm, Ulm, Germany, ${ }^{2}$ Department of Human Genetics, Hannover Medical School, Hannover, Germany, ${ }^{13}$ Department of Pediatric Hematology and Oncology, JustusLiebig-University, Giessen, Germany, ${ }^{14} \mathrm{Clinic}$ of Pediatric Hematology and Oncology, University Medical Center HamburgEppendorf, Hamburg, Germany, ${ }^{15}$ Hemato-Oncology Clinic Hamburg, Hamburg, Germany, ${ }^{16}$ Faculty of Medicine, Institute of Pathology, Medical Center, University of Freiburg, Freiburg, Germany, ${ }^{17}$ German Cancer Consortium (DKTK), Freiburg, Germany, ${ }^{18}$ German Cancer Research Center (DKFZ), Heidelberg, Germany, ${ }^{19}$ Department of Pediatrics and Adolescent Medicine, Medical University of Vienna, Vienna, Austria, ${ }^{20}$ St. Anna Kinderspital and Children's Cancer Research Instutute, Department of Pediatrics and Adolescent Medicine, Medical University of Vienna, Vienna, Austria

Typical features of dyskeratosis congenita (DC) resulting from excessive telomere shortening include bone marrow failure (BMF), mucosal fragility, and pulmonary or liver fibrosis. In more severe cases, immune deficiency and recurring infections can add to disease severity. RTEL1 deficiency has recently been described as a major genetic etiology, but the molecular basis and clinical consequences of RTEL1-associated DC are incompletely characterized. We report our observations in a cohort of six patients: five with novel biallelic RTEL1 mutations p.Trp456Cys, p.lle425Thr, p.Cys1244ProfsX17, p.Pro884_Gln885ins53X13, and one with novel heterozygous mutation p.Val796AlafsX4. The most unifying features were hypocellular BMF in 6/6 and B-/NK-cell lymphopenia in 5/6 patients. In addition, three patients with homozygous mutations p.Trp456Cys or p.lle425Thr also suffered from immunodeficiency, cerebellar hypoplasia, and enteropathy, consistent with Hoyeraal-Hreidarsson syndrome. Chromosomal breakage resembling a homologous recombination defect was detected in patient-derived fibroblasts but not in hematopoietic compartment. Notably, in both cellular compartments, differential expression of 1243aa and 1219/1300aa RTEL1 isoforms was observed. In fibroblasts, response to ionizing irradiation and non-homologous end joining were not impaired. Telomeric circles did not accumulate in patient-derived primary cells and lymphoblastoid cell lines, implying alternative pathomechanisms for telomeric loss. Overall, RTEL1-deficient cells 
exhibited a phenotype of replicative exhaustion, spontaneous apoptosis and senescence. Specifically, CD34+ cells failed to expand in vitro, B-cell development was compromised, and T-cells did not proliferate in long-term culture. Finally, we report on the natural history and outcome of our patients. While two patients died from infections, hematopoietic stem cell transplantation (HSCT) resulted in sustained engraftment in two patients. Whether chemotherapy negatively impacts on the course and onset of other DC-related symptoms remains open at present. Early-onset lung disease occurred in one of our patients after HSCT. In conclusion, RTEL deficiency can show a heterogeneous clinical picture ranging from mild hypocellular BMF with B/NK cell lymphopenia to early-onset, very severe, and rapidly progressing cellular deficiency.

Keywords: RTEL1, dyskeratosis congenita, bone marrow failure, immunodeficiency, lymphopenia

\section{INTRODUCTION}

Dyskeratosis congenita (DC) comprises a group of Mendelian disorders marked by intrinsic telomere shortening, caused by defects in genes involved in telomere homeostasis. The varied clinical phenotype and delayed onset of non-hematological symptoms can render the diagnosis of DC difficult. The classical form of DC is characterized by bone marrow failure (BMF), mucocutaneous features, and pulmonary and/or hepatic fibrosis (1-4). In patients with severe and early-onset disease, also referred to as Hoyeraal-Hreidarsson syndrome (HHS), in addition to $\mathrm{BMF}$, the disease is distinguished by intrauterine growth retardation, microcephaly/cerebellar hypoplasia, and increased susceptibility to infections due to cellular and humoral immunodeficiency (5-7). The most consistent immunological phenotype is a combined decrease in B- and NK-cells with usually normal numbers and in vitro function of T-cells (8).

Until recently, HHS has been associated with mutations in TINF2 (heterozygous), DKC1 (X-linked), or TERT (homozygous) but its cause remains elusive in approximately half of the patients (1). Ballew et al. and Walne et al. first reported the identification of biallelic RTEL1 mutations in patients with HHS $(9,10)$. To date, 30 distinct mutations have been reported in 24 unrelated pedigrees, in patients suffering from similar clinical features including BMF, B-/NK-cell lymphopenia, and developmental delay (9-20). In addition, heterozygous missense variants in RTEL1 have been identified in association with idiopathic pulmonary fibrosis, reported in 10 pedigrees (21-23). RTEL1 is a helicase essential in DNA metabolism (24-27) and has been classified as a helicase with a conserved iron-sulfur (FeS) cluster. Other disorders resulting from mutations in FeShelicase genes include Xeroderma pigmentosum (XPD), Warsaw breakage syndrome (DDX11/ChIR1), and Fanconi anemia group $\mathrm{J}(F A N C J)$. Despite similar pathophysiological basis, the clinical and biological phenotypes are different in these entities $(25,28)$. Inappropriate resolution of the telomeric-loops (T-loops) into free telomeric circles (T-circles) has been postulated as the mechanism underlying catastrophic telomere shortening and cellular defect in RTEL1 deficiency (10). However, due to the limited experimental studies in patients, the molecular basis of the clinical phenotype has remained incompletely characterized.
Here, we examined the natural history and treatment outcome of six patients with five novel RTEL1 mutations. To better understand the functional consequences of identified mutations, we employed molecular and cellular assays in patient-derived primary cells, long-term culture, and manipulated cell lines. We ascribe a premature truncation effect on mRNA level to the splice site mutation c. $2652+5 \mathrm{G}>\mathrm{A}$. We also demonstrate normal $\mathrm{V}(\mathrm{D}) \mathrm{J}$ recombination and unaffected T-loop disassembly with normal numbers of T-circles in RTEL1-deficient patients, extending previous findings in RTEL1 deficiency. Our clinical and experimental observations support the notion of early proliferative exhaustion along with spontaneous apoptosis, increased senescence, and rapid telomere shortening in RTEL1-mutated cells. Moreover, we report on the clinical course of hematopoietic stem cell transplantation (HSCT) in two of our patients.

\section{MATERIALS AND METHODS}

\section{Telomere Length Assessment and Genetic Studies}

For initial explorative analysis, the relative telomere length (RTL) was measured from DNA of granulocytes using quantitative multiplex real-time polymerase chain reaction (PCR) according to Cawthon (29). In-house reference values from peripheral blood (PB) and bone marrow (BM) granulocytes of 90 healthy BM donors (age 2-18 years) were used for percentile calculation. RTL [telomere to single copy gene (T/S) ratio] was calculated as median from at least two independent triplicate runs. The intraassay coefficient of variation $(\mathrm{CV})$ ranged from 0 to $6 \%$ (mean $3.75 \%$ ), and inter-assay CV was $2-11 \%$ (mean $7 \%$ ). Telomere length was validated using metaphase telomere/centromerefluorescence in situ hybridization (T/C-FISH) in a second laboratory, as previously described (30).

\section{Cell Culture and Immunological Studies}

Primary fibroblasts were grown in DMEM medium containing $20 \%$ FCS and 1\% P/S and tested mycoplasma free. For hematopoietic cell cultures, mononuclear cells (MNCs) were isolated from BM of patients and healthy control using Ficoll-based density gradient centrifugation, and magnetically isolated CD $34^{+}$ 
cells (MACS Miltenyi) were cultured for 7 days with IL6, SCF, and FLT3-L. T-cell proliferation, flow cytometric analysis of lymphocyte subsets, $\mathrm{T}$-cell receptor $\mathrm{V} \beta$-repertoire, and T-cell cytokine production were assessed as previously reported $(31,32)$. For analysis of ex vivo survival, MNCs were cultured for 6 days. At days $0,1,2,3$, and $6,2 \times 10^{5}$ cells were stained with Annexin V (AV) and PI (BD Biosciences) and analyzed by flow cytometry. Degranulation of T- and NK-cells was assessed as previously reported (33).

\section{Senescence-Associated $\beta$-Galactosidase Staining}

Primary fibroblasts from healthy control, P1, and a patient with known DC and TERC mutation were fixed for $5 \mathrm{~min}$ in $2 \% \mathrm{vol} /$ vol paraformaldehyde in PBS, washed in PBS, and stained in $\beta$-galactosidase fixative solution (X-gal) in $5 \mathrm{mmol} / \mathrm{l}$ potassium ferricyanide, $5 \mathrm{mmol} / \mathrm{l}$ potassium ferrocyanide, and $2 \mathrm{mmol} / \mathrm{l}$ $\mathrm{MgCl}_{2}$ in $\mathrm{PBS}$ for $16 \mathrm{~h}$ at $37^{\circ} \mathrm{C}$. Controls and patient cells were analyzed at the same passage number, 200 cells were counted per well, and staining performed in triplicates.

\section{Radiosensitivity and Mitomycin C (MMC)-Induced Chromosomal Breakage}

Primary fibroblasts were seeded at a density of 4,000 cells $/ \mathrm{cm}^{2}$. Parallel cultures were grown in DMEM with GlutaMAX (Gibco) and supplemented with 15\% FBS (PAN). For flow cytometry, $48 \mathrm{~h}$ cultures were left untreated or exposed to $10 \mathrm{ng} / \mathrm{ml} \mathrm{MMC}$ (Medac) or initially irradiated with 1.5 Gy from a linear accelerator. Cells were detached using $1 \times(0.05 \%)$ trypsin (diluted from trypsin $0.5 \%$-EDTA $0.2 \%$ solution $10 \times$, PAA), pelleted, and stained in medium containing $15 \mu \mathrm{g} / \mathrm{ml}$ Hoechst dye 33342 (Molecular Probes) for $30 \mathrm{~min}$ in the dark. Gates were set on vital cells via propidium iodide (PI, $1 \mu \mathrm{g} / \mathrm{ml}$ ) exclusion. Split samples were stained with $1 \mu \mathrm{g} / \mathrm{ml} 4^{\prime}$,6-diamidino-2-phenylindole (DAPI; Molecular Probes) in buffer containing $154 \mathrm{mM} \mathrm{NaCl}, 0.1 \mathrm{M}$ Tris $\mathrm{pH} 7.4,1 \mathrm{mM} \mathrm{CaCl}_{2}, 0.5 \mathrm{mM} \mathrm{MgCl}_{2}, 0.2 \% \mathrm{BSA}$, and $0.1 \% \mathrm{NP} 40$ in $\mathrm{dH}_{2} \mathrm{O}$. Univariate flow histograms were recorded on a triplelaser equipped LSRII flow cytometer (Becton Dickinson) using UV excitation of Hoechst 33342 or DAPI, and 488-nm excitation of PI. Resulting cell cycle distributions reflecting cellular DNA content were quantified using the MPLUS AV software package (Phoenix Flow Systems).

\section{Cytogenetic Analyses for Visualization of Chromosomal Breakage}

Fibroblasts were exposed to MMC at final concentrations of 0,10 , 50 , or $100 \mathrm{ng} / \mathrm{ml}$ for the final $24 \mathrm{~h}$ of culture. For the last $3 \mathrm{~h}, 16 \mu \mathrm{l}$ of Colcemid Solution $(10 \mu \mathrm{g} / \mathrm{ml}$; PAA) per milliliter of growth medium were added. Metaphase preparation followed standard procedures. Detachment of cells was evaluated by trypsin as above. Pellets were subjected to hypotonic treatment using $10 \mathrm{ml}$ of pre-warmed $0.075 \mathrm{M} \mathrm{KCl}$ for $10 \mathrm{~min}$ at $37^{\circ} \mathrm{C}$. Nuclei and metaphases were fixed using freshly prepared, ice-cold $100 \%$ methanol, and glacial acetic acid 3:1. A minimum of 50 complete metaphases from Giemsa-stained slides of each MMC concentration were scored quantitatively for breakage rates and analyzed qualitatively for types of chromosome aberrations.

\section{V(D)J Recombination Assay}

$\mathrm{V}(\mathrm{D}) \mathrm{J}$ recombination assays were performed as described previously (34). In short, human primary RTEL1-proficient or RTEL1deficient dermal fibroblasts were transfected using the Cell Line V Nucleofector Kit (Lonza, Cologne, Germany). Transfections were performed with $1.2 \mu \mathrm{g}$ pcWT-RAG1, $1.8 \mu \mathrm{g}$ pcWT-RAG2, 8.0 $\mu \mathrm{g}$ pMACS11-19VDJ, or pMACS11-19Flip, and $1.0 \mu \mathrm{g}$ pcDNA6/myc-His Version A (Invitrogen, Life Technologies, Darmstadt, Germany). After $48 \mathrm{~h}$, cells were harvested and analyzed by immunofluorescence flow cytometry. Transfected fibroblasts were detected with biotin-anti mouse $\mathrm{H}-2 \mathrm{Kk}$ antibody (BD Biosciences, San Jose, CA, USA) against the truncated murine major histocompatibility complex class I protein $\mathrm{H}-2 \mathrm{Kk}$ additionally encoded by the pMACS11-19VDJ and pMACS1119Flip plasmids. The biotin-labeled antibodies were detected by streptavidin-peridinin chlorophyll protein staining (BD Biosciences). Assays were performed three times independently for the two tested cell lines. The arithmetic means of the three values and the corresponding SDs were calculated.

\section{T-Circle Analysis}

The analysis of telomeric T-circles was performed as previously described (27) using patient fibroblasts (P1, P3), T-lymphoblasts (P1 and family members, P5), and cell lines [VA13 ALT, Rtel1 $^{-/-}$mouse embryonic fibroblasts (MEFs), Rtel1 ${ }^{\mathrm{F} / \mathrm{F}} \mathrm{MEFs}$, and BJhTERT] and as positive control fibroblasts with homozygous mutation p.Arg1264His known to exhibit T-circle loss.

\section{Genomic Studies}

\section{Exome Sequencing (ES) Studies and Protein Modeling}

For homozygosity mapping in P1 and P2, homozygous regions were mapped as described before (35). In brief, genomic DNA was treated according to the Affymetrix ${ }^{\circledR}$ Genome-Wide Human SNP Nsp/Sty 6.0 protocol. Results were assessed using the Affymetrix ${ }^{\circledR}$ Genotyping Console ${ }^{\mathrm{TM}}$ software, PLINK (36).

\section{ES in $P 1$ and $P 2$}

The sample was prepared using the Illumina TruSeq DNA Sample Preparation Guide, the Illumina TruSeq Exome Enrichment Guide version 3, and the TruSeq PE Cluster Kit v3 Reagent Preparation Guide. Data were analyzed by applying Burrows-Wheeler Aligner for the alignment of the reads and the Genome Analysis Toolkit $(37,38)$ for quality score recalibration as previously described (35). Annotation was done using the ANNOVAR (39).

\section{Variant Validation}

The variants of the final hit list were validated with capillary sequencing on genomic DNA from the patients, using Big Dye Terminator v3.1 Cycle Sequencing Kit (Applied Biosystems, Germany) on a 3130xl Genetic Analyzer (Applied Biosystems).

\section{Protein Modeling and Phylogenetic Conservation}

The protein model (AA 1-754) was created using I-TASSER (39) based on the crystal structure of the protein database molecule 2vsfA (40) (sequence homology 20\%). Secondary structures were assigned with the program ICM-Browser, Molsoft LLC. Phylogenetic conversation was assessed using Polyphen-2. 


\section{Targeted Sequencing Using Sanger Sequencing}

DNA was extracted using Gentra Puregene DNA kit (Qiagen) from PB. PCR and cycle sequencing products were purified using standard enzymatic or sephadex-based cleanup.
PCR and Sanger sequencing were performed as previously described (41).

Primers used for amplification and sequencing of genomic DNA:

\begin{tabular}{|c|c|c|c|}
\hline Exon & Forward & Reverse & $\mathrm{MgCl}_{2}(\mathrm{mM})$ \\
\hline 3 & GССTCTGCATCTGCAAAGAG & CTTGAGTTCTGCTTGAGAGAC & 2.2 \\
\hline $5-6$ & TCСTCССTCTGTCCAGTAC & CAAGCACAACCAGGCTGTG & 1.5 \\
\hline 7 & CCTCAGTGGGTGCTITGTG & АСTCTATCTTCCTCAGAGCTG & 2.2 \\
\hline 8 & CAGGATGAGGGCTCCTTC & CCCAGTGACAGAGGTGAG & 1.5 \\
\hline 9 & CTCATCTGCGCTTGTGATGT & CACCTAGGGCTTCAGGAG & 2.2 \\
\hline 12 & AGACATTGCAAAGCTGAAGAG & GATGTGACAGCCCAGGAC & 1.5 \\
\hline 13 & ACTTCCACAGTTGTTGCCTTC & GCTGGCAAGTGGCACTAAC & 1.5 \\
\hline 14 & GAGATGGAGCTTGGCAGTC & CTGGAAAGGAGCCGAGAG & 2.2 \\
\hline $15-16$ & AGAAAGGGTCAGGCAGGTG & TGAGGAGAATGCTCTGGATTG & 2.2 \\
\hline $17-18$ & AAGCTGGCAGGCTCACAC & САCTCACCCAGAGCCTTC & 1.5 \\
\hline $19-21$ & TGGAGAACCCACACATCATC & AGGAGCCCTGAAGAGGCA & 1.5 \\
\hline 28 & AAGTTGTGGCACTGTCACC & GGCTGTGTCCCTCACATG & 2.2 \\
\hline 29-30 & CCAGTTCTCAGGCAGCAG & CTCCCATAGGGGAACAGAG & 2.2 \\
\hline 31 & AGGCTGGTGTCTCCTCTGA & AGCAGTCCCCACCATGAGA & 1.5 \\
\hline 32 & GGCTTCACGAGGCTAACTC & CTITGCTGCTCACTCCCAG & 1.5 \\
\hline 33-34 & CAACTCTTGGCAGCGCTGA & TGAAGGTGCCGTTGCCAG & 2.2 \\
\hline $34-35$ & CTCCTGTGCTTACCCACAG & CTATTCTGTTGGGTGGGTTC & 2.2 \\
\hline 36 & AGGTGGCATGTCGGTCAG & TTGTGGGTGGCGTGGCAA & 2.2 \\
\hline
\end{tabular}

\section{RT-PCR}

RNA was prepared according to standard methods (TRIZOL, Invitrogen Lifetech, USA). cDNA was generated from $1 \mu \mathrm{g}$ of RNA using the QuantiTect Reverse Transcription Kit (Qiagen, Germany). Reverse transcriptase was not added in RT minus $\left(\mathrm{RT}^{-}\right)$reactions, used for exclusion of genomic DNA contamination and thus unspecific amplification of genomic DNA in the RT-PCR. The PCR master mix was set up as follows: $6 \mu$ l of $5 \times$ PCR buffer, $3 \mu \mathrm{l}$ of $2 \mathrm{mM}$ deoxynucleoside triphosphates, $1 \mu \mathrm{l}$ of $10 \mu \mathrm{M}$ each forward and reverse primers, $0.2 \mu \mathrm{l}$ of Taq
(5 U/ $\mu \mathrm{l}$; Go Taq DNA Polymerase, Promega), $\mathrm{MgCl}_{2}$ (final $2.2 \mathrm{mM}$ ), and $2 \mu \mathrm{l}$ of cDNA were mixed with sterile water to a final volume of $30 \mu \mathrm{l}$. Thermocycling was performed on a Peqstar Thermocycler (Peqlab, Germany). After an initial denaturation step at $94^{\circ} \mathrm{C}$ for $2 \mathrm{~min}$ and 17 touch-down cycles (denaturation at $94^{\circ} \mathrm{C}$ for $30 \mathrm{~s}$; annealing at $63^{\circ} \mathrm{C},-0.5^{\circ} \mathrm{C}$ per step, for $30 \mathrm{~s}$; and extension at $72^{\circ} \mathrm{C}$ for $30 \mathrm{~s}$ ), an additional 20 PCR cycles were performed $\left(30 \mathrm{~s}\right.$ at $94^{\circ} \mathrm{C}, 30 \mathrm{~s}$ at $55^{\circ} \mathrm{C}$, and $30 \mathrm{~s}$ at $\left.72^{\circ} \mathrm{C}\right)$.

RTEL1 cDNA primers:

\begin{tabular}{|c|c|c|c|}
\hline Ex3-4 fw & AGACCCCATAGCTTGCTACA & Ex6-7 rev & TCTGTAGATGGTTACTCTCTTG \\
\hline Ex26-27 fw & AGGTCCTCAGGGTCACCAG & Ex30-31 rev & GTTCTTCCAGTGGGGTCCAG \\
\hline Ex34-35 fw & GCACCTTCAGGCCTCTAG & Ex36 rev & GACGTTGCAGTAGCGGCA \\
\hline
\end{tabular}

\section{RESULTS}

\section{Clinical Phenotype and Natural History of Patients with RTEL1 Mutations}

The essential clinical and laboratory data of our patients are summarized in Tables $\mathbf{1}$ and 2, key clinical featured of the index patient are shown in Figure 1, and the pedigrees of the investigated families are shown in Figure 2A.
Patient P1 (Family 1) was brought to our attention for recurring bacterial and viral pneumonias manifesting from 9 months of age. Pancytopenia, B/NK-cell lymphopenia, and hypogammaglobulinemia were subsequently noted. In short span, the manifestation of leukoplakia and ataxia associated with cerebellar hypoplasia led to the clinical diagnosis of HHS (Figures 1A-C). Between 2 and 3 years of age, P1 developed refractory noninfectious diarrhea and long-segment esophageal narrowing. An 
TABLE 1 | Clinical phenotype of patients 1-6.

\begin{tabular}{|c|c|c|c|c|c|c|}
\hline Clinical phenotype & P1 & P2 & P3 & P4 & P5 & P6 \\
\hline Ethnic origin & \multicolumn{2}{|c|}{ Turkish } & \multicolumn{2}{|l|}{ Moroccan } & German & German \\
\hline Gender & Female & Male & Male & Female & Male & Male \\
\hline $\begin{array}{l}\text { Age/initial presentation at disease } \\
\text { onset }\end{array}$ & 9 months/infections & $\begin{array}{l}3 \text { months/ } \\
\text { failure to thrive }\end{array}$ & 12 months/leukoplakia & $\begin{array}{l}4 \text { years/ } \\
\text { diarrhea }\end{array}$ & $\begin{array}{l}9 \text { years/pancytopenia and } \\
\text { infections }\end{array}$ & $\begin{array}{l}19 \text { years/ } \\
\text { thrombocytopenia }\end{array}$ \\
\hline Age at last follow-up & 7 years 4 months & 19 months & 7 years 8 months & $\begin{array}{l}7 \text { years } \\
8 \text { months }\end{array}$ & 21 years & 19 years \\
\hline Treatment & MFD HSCT & None & $\begin{array}{l}\text { Matched unrelated } \\
\text { donor HSCT }\end{array}$ & $\begin{array}{c}\text { Careful } \\
\text { watching }\end{array}$ & Oxymetholone & None \\
\hline Outcome & $\begin{array}{c}\text { Alive } \\
\text { (HSCT }+4 \text { years } \\
2 \text { months })\end{array}$ & $\begin{array}{l}\text { Deceased } \\
\text { (CMV) }\end{array}$ & $\begin{array}{l}\text { Alive (HSCT } 2 \text { years } \\
6 \text { months) }\end{array}$ & Alive & Deceased (pneumonia) & Alive \\
\hline RTEL 1 mutations & \multicolumn{2}{|c|}{ c.1368G>T; p.Trp456Cys hom } & \multicolumn{2}{|c|}{ c.1274T>C; p.lle425Thr hom } & $\begin{array}{l}\text { c. } 2652+5 G>C ; \\
\text { p.Pro884_GIn885ins53X13 } \\
\text { het and c.3730delTG; } \\
\text { p.Cys1244ProfsX17 het }\end{array}$ & $\begin{array}{l}\text { c.2387delT; } \\
\text { p.Val796AlafsX4 } \\
\text { het }\end{array}$ \\
\hline
\end{tabular}

\begin{tabular}{|c|c|c|c|c|c|c|}
\hline \multicolumn{7}{|c|}{ Major dyskeratosis congenita (DC) features ${ }^{a}$} \\
\hline Bone marrow failure & + & + & + & - & + & + \\
\hline Oral leukoplakia & + & + & + & - & + & - \\
\hline Abnormal skin pigmentation & - & - & - & - & - & - \\
\hline Nail dystrophy & - & - & - & - & + & - \\
\hline Telomere length < first percentile & + & + & + & + & + & + \\
\hline \multicolumn{7}{|l|}{ Other DC-related features } \\
\hline Ataxia/cerebellar hypoplasia on MRI & $+/+$ & $+/+$ & $+/+$ & $-/$ n.i. & $-/$ n.i. & $-/$ n.i. \\
\hline IUGR & + & - & - & - & + & - \\
\hline Short stature & + & + & + & - & - & - \\
\hline Microcephaly & + & + & + & - & + & - \\
\hline Developmental delay & + & + & + & - & - & - \\
\hline Esophageal stricture or Gl ulcerations & + & - & + & - & + & - \\
\hline Lung fibrosis/liver cirrhosis & $+/-$ & $-/-$ & $-1-$ & $-1-$ & $-/+$ & $-1-$ \\
\hline Chronic diarrhea & + & + & + & + & + & - \\
\hline T+B-NK- immune phenotype & + & + & + & + & + & - \\
\hline MMC-induced chromosomal breakage & $\begin{array}{c}+ \text { fibroblasts } \\
\text { - blood }\end{array}$ & n.i. & $\begin{array}{c}+ \text { fibroblasts } \\
\text { - blood }\end{array}$ & n.i. & - blood & n.i. \\
\hline Systemic infections & \multicolumn{2}{|c|}{ Viral and bacterial } & Bacterial & None & Viral and bacterial & none \\
\hline
\end{tabular}

${ }^{a}$ As defined in Dokal (1).

hom, homozygous; het, heterozygous; +, present; -, absent; n.i., not investigated; MFD HSCT, matched family donor hematopoietic stem cell transplantation; IUGR, intrauterine growth retardation; MMC, mitomycin $C$.

increased apoptotic rate within the colon and esophageal mucosa was detected by endoscopy (Figures 1E,F). Due to rapidly progressing BMF (Figure 1G) and immunodeficiency, P1 was transplanted from her HLA-identical grandmother (further details are described below). Similar clinical symptoms were observed in P2, a second-degree cousin of P1 (Figure 2A). Within first 3 months after birth, P2 had failure to thrive and microcephaly, with recurrent infections manifesting from age of 5 months. He died at the age of 19 months due to systemic CMV infection.

Two further patients (P3 and P4) belong to Family 2 (Figure 2A). P3 initially developed leukoplakia at age of 12 months; however, his leading medical concerns were developmental delay and BMF diagnosed at age of 2 years and 9 months. He was successfully transplanted from a 9/10 matched unrelated donor (MUD) at 5.2 years of age. Identical homozygous RTEL1 mutation was identified in his twin sister (P4) by family screening. P4 initially presented with mild chronic diarrhea, high MCV and NK-cell lymphopenia, and short telomeres at the age of approximately 4 years, but later also developed mild leukoplakia (Tables 1 and 2).

P5 from Family 3 (Figure 2A) suffered from recurrent infections beginning from 6 years of age and progressive BMF after EBV infection at 9 years of age. In contrast to P1-P4, he developed severe mucosal fragility, nail dystrophy, and liver cirrhosis with secondary hypersplenism (Table 1). He became transfusion dependent for RBC and platelets at 15 years of age. Oxymetholone therapy initiated at age of 20 years later resulted in transfusion independency for platelets. However, infectious complications intensified and he died of sepsis after pneumonia at 21 years of age.

P6 from Family 4 (Figure 2A) was born to non-consanguineous parents with an uneventful family history. Postnatal development was normal and he was asymptomatic at diagnosis when he was 17 years old. Complete blood count performed prior to surgery 
TABLE 2 | Extended laboratory findings of patients with RTEL1 mutations.

\begin{tabular}{|c|c|c|c|c|c|c|}
\hline Laboratory tests & P1 & P2 & P3 & P4 & P5 & P6 \\
\hline \multicolumn{7}{|l|}{ Blood count, lowest observed values } \\
\hline Hemoglobin, g/dl (N: 13.5-17.5) & 6.0 & 6.4 & 5.0 & 12.4 & 6.0 & 15.6 \\
\hline Platelets, 10\%/l (N: 150-450) & 23 & 25 & 24 & 288 & $<10$ & 63 \\
\hline WBC, $10^{9} /(N: 4,500-11,000)$ & 1,100 & 3,500 & 1,020 & 4,400 & 100 & 3,900 \\
\hline ANC, $10^{6} / 1(N: 1,500-8,000)$ & 70 & 1,300 & 620 & 2,080 & 50 & 1,290 \\
\hline Lymphocytes, $10^{6} / \mathrm{I}(\mathrm{N}: 1,000-4,800)$ & 770 & 2,100 & 290 & 1,650 & 50 & 1,000 \\
\hline MCV > 95th percentile & Yes & No & Yes & Yes & Yes & Yes \\
\hline \multicolumn{7}{|l|}{ T-cells } \\
\hline $\mathrm{CD}^{+} / \mu \mathrm{l}$ & 724-937 (2,100-6,200) & $970-1,538(2,100-6,200)$ & $2,016(700-4,200)$ & 1,480-1,949 (700-4,200) & $140(700-2,100)$ & $1,254(700-2,100)$ \\
\hline $\mathrm{CD}_{4}^{+} / \mu \mathrm{l}$ & $457-561(1,300-3,400)$ & $790-1,172(1,300-3,400)$ & $1,258(300-2,000)$ & $740-1,011(300-2,000)$ & $60(300-1,400)$ & $818(300-1,400)$ \\
\hline $\mathrm{CD} 8^{+} / \mu \mathrm{l}$ & $251-350(620-2,000)$ & $176-357(620-2,000)$ & $724(300-1,800)$ & $670-835(300-1,800)$ & $70(200-900)$ & 357 (200-900) \\
\hline$\% \gamma / \delta \mathrm{TCR}^{+}$of $\mathrm{CD}^{+}$ & $2(<10)$ & $0.8(<10)$ & $1.1(<10)$ & $6.3(<10)$ & n.a. & $6.4(<10)$ \\
\hline$\%$ CD45RA of CD4+ & $71-79(63-91)$ & $84(63-91)$ & $66(53-86)$ & $62(53-86)$ & 25 (33-66) & $51(33-66)$ \\
\hline B-cells CD19+/ $\mu$ l & $1-26(720-2,600)$ & $2-47(720-2,600)$ & $26-74(200-1,600)$ & 230-252 (200-1,600) & $2(100-500)$ & $162(100-500)$ \\
\hline NK cells: CD3-D16+CD56 $+\mu \mathrm{l}$ & 30-63 (180-920) & $4-23(180-920)$ & $4-10(90-900)$ & $20-50(90-900)$ & $20(90-600)$ & $105(90-600)$ \\
\hline \multicolumn{7}{|l|}{ Immunoglobulins (maximal values) } \\
\hline $\lg G / \lg A / \operatorname{lgM}, \mathrm{g} / \mathrm{l}$ & $<1 / 0.1 / 0.25$ & $4.5 / 0.4 / 0.4$ & $13.9 / 2.3 / 0.6$ & $9.8 / 1.1 / 0.5$ & $5.3 / 0.3 /<0.2$ & n.a. \\
\hline $\lg \mathrm{E}, \mathrm{kU} / \mathrm{l}$ & 2.1 & $<2$ & 24.7 & 24 & n.a. & n.a. \\
\hline Specific lgGa & - (EBV, CMV, VZV, tetanus) & + (rubella, hepatitis B) & $\begin{array}{l}+(\mathrm{EBV}, \mathrm{CMV} \text {, tetanus, } \\
\text { measles, mumps, rubella) }\end{array}$ & $\begin{array}{l}+(\mathrm{CMV}, \mathrm{VZV}, \mathrm{PB} 19, \text { tetanus, } \\
\text { measles, mumps, rubella) }\end{array}$ & $\begin{array}{l}\text { - (EBV, CMV, VZV, } \\
\text { PB19, measles, } \\
\text { mumps, rubella) }\end{array}$ & n.a. \\
\hline T-cell proliferation: PHA/anti-CD3 & norm/norm & n.a./n.a. & norm/n.a. & n.a./n.a. & norm/n.a. & n.a/n.a. \\
\hline
\end{tabular}

${ }^{a}$ All patients were exposed to the indicated antigens either by vaccination or infection and specific lg $G$ were measured prior to i.v. application of immunoglobulins.

+, present; -, absent; n.a., not available; norm, normal; WBC, white blood count; ANC, absolute neutrophil count; MCV, mean corpuscular volume; PHA, phytohemagglutinine.

Normal age-related values are depicted in parentheses. Italic formatting indicates laboratory values below the age-related normal range. 


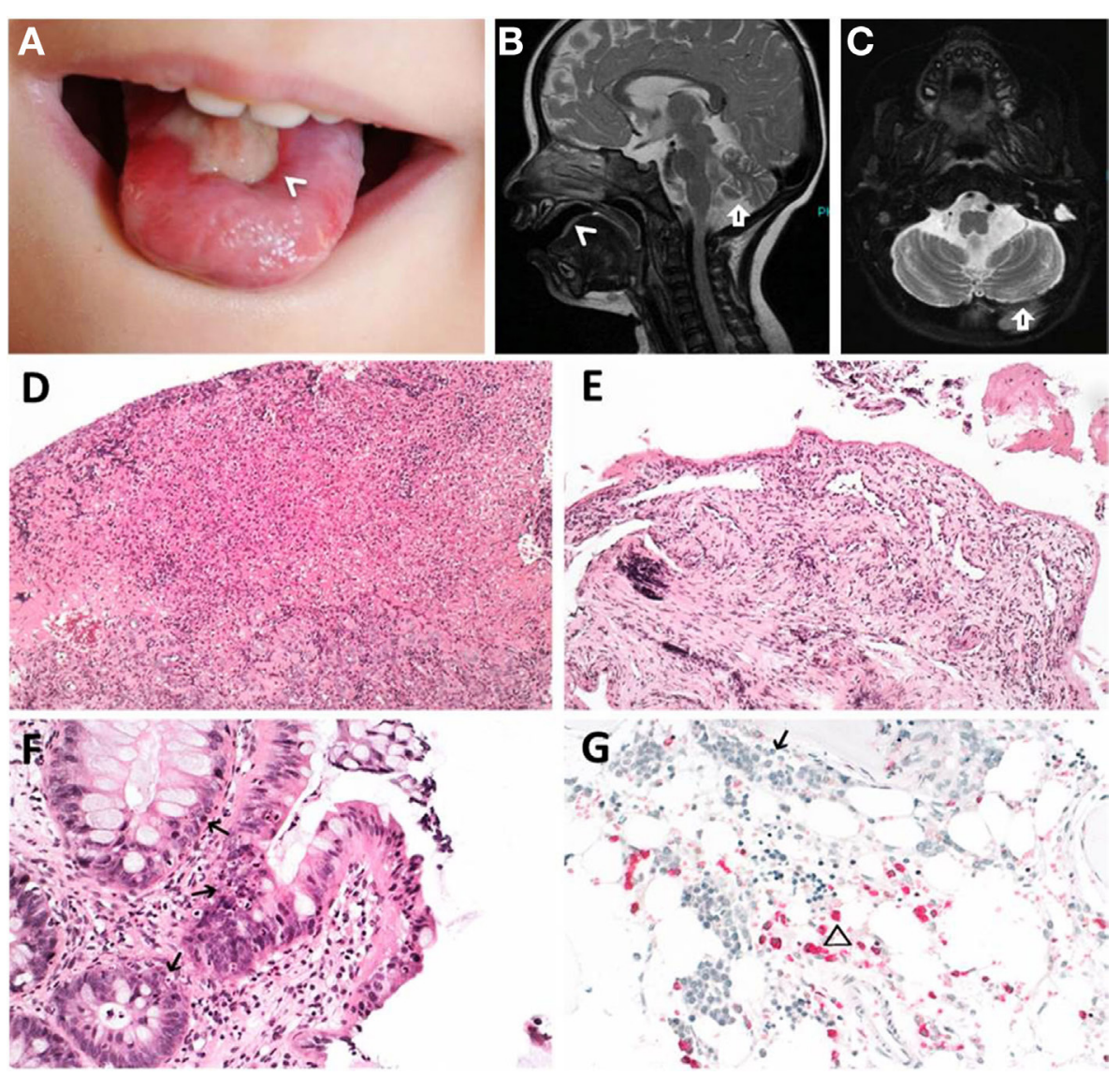

FIGURE 1 | Clinical features of index patient 1 (P1). (A-C) Leukoplakia (<), sinistral cerebral hypoplasia (arrow). (D) Granulation tissue of tongue and (E) esophageal ulcers. (F) Apoptotic bodies in colon (arrows). (G) Hypocellular bone marrow before hematopoietic stem cell transplantation with immature erythropoiesis (arrow) and sparse myeloid precursors (triangle). (D-F) Hematoxylin and eosin staining, (G) naphthol-AS-D-chloroacetate esterase (NACE) staining.

for a shoulder dislocation revealed thrombocytopenia and elevated MCV (Tables 1 and 2). These findings prompted further investigations and a BM biopsy was compatible with the histological diagnosis of hypocellular refractory cytopenia. Telomere analysis and full DC-genetic workup eventually identified RTEL1 deficiency. Family history revealed no malignancies in all patients or their first-degree relatives.

At the time when our index patients P1 and P2 were studied, disease-causing mutations in RTEL1 were not yet reported. We therefore used Sanger sequencing to exclude mutations in nine known DC-related genes, followed by homozygosity mapping and ES. Three variants (COL9A3 $3^{\mathrm{Arg} 103 \mathrm{Gln}}$, PRIC285 $5^{\mathrm{Glu} 615 \mathrm{Lys}}$, and RTEL1 $1^{\text {Trp456Cys }}$ ) segregated with the disease (Table 3). RTEL1 was the most plausible candidate gene, given its essential role in telomere maintenance and coinciding reports on RTEL1 mutations (Figure 2B). The homozygous mutation p.Trp456Cys affects a protein region with a very high degree of homology in all 17 species and is located in a $\beta$-sheet (Figures 3A,C). Targeted re-sequencing identified four additional RTEL1 mutations in P3-P6 (Figures 2A and 3B). Parents of twins P3 and P4 are firstdegree cousins and transmit the heterozygous missense mutation p.Ile425Thr; both P3 and P4 are homozygous, while their healthy siblings are heterozygous carriers (Figure 2A) and have normal RTL (not shown). The RTEL1 amino acid Ile425 is located in the $\alpha$-helix and found to be conserved in 16 out of 17 tested species (Figures 3B,D). Finally, a compound heterozygous state with one truncating splice site mutation c. $2652+5 \mathrm{G}>\mathrm{A}$ in intron 28 and a frameshift mutation c.3730delTG; p.Cys1244ProfsX17 in exon 34b of RTEL1 was identified in P5 (Figure 2A). P6 was the only patient in this study who carried solely a heterozygous nonsense mutation p.Val796AlafsX4 resulting in premature stop codon prior to both C-terminal harmonin domains. This mutation could not be investigated on functional level in primary patient cells due to lack of available material.

\section{RTEL1 Isoforms and Consequences of Mutations}

The longest four of the seven Ensembl-annotated, protein coding isoforms are shown in Figure 4A. Mutation nomenclature in this manuscript refers to the 1300aa isoform (NM_001283009), which along with the 1219aa isoform (NM_016434) is predominantly expressed in human cells, and also served as a reference for the majority of reported mutations (Figure 2B). Notably, the 


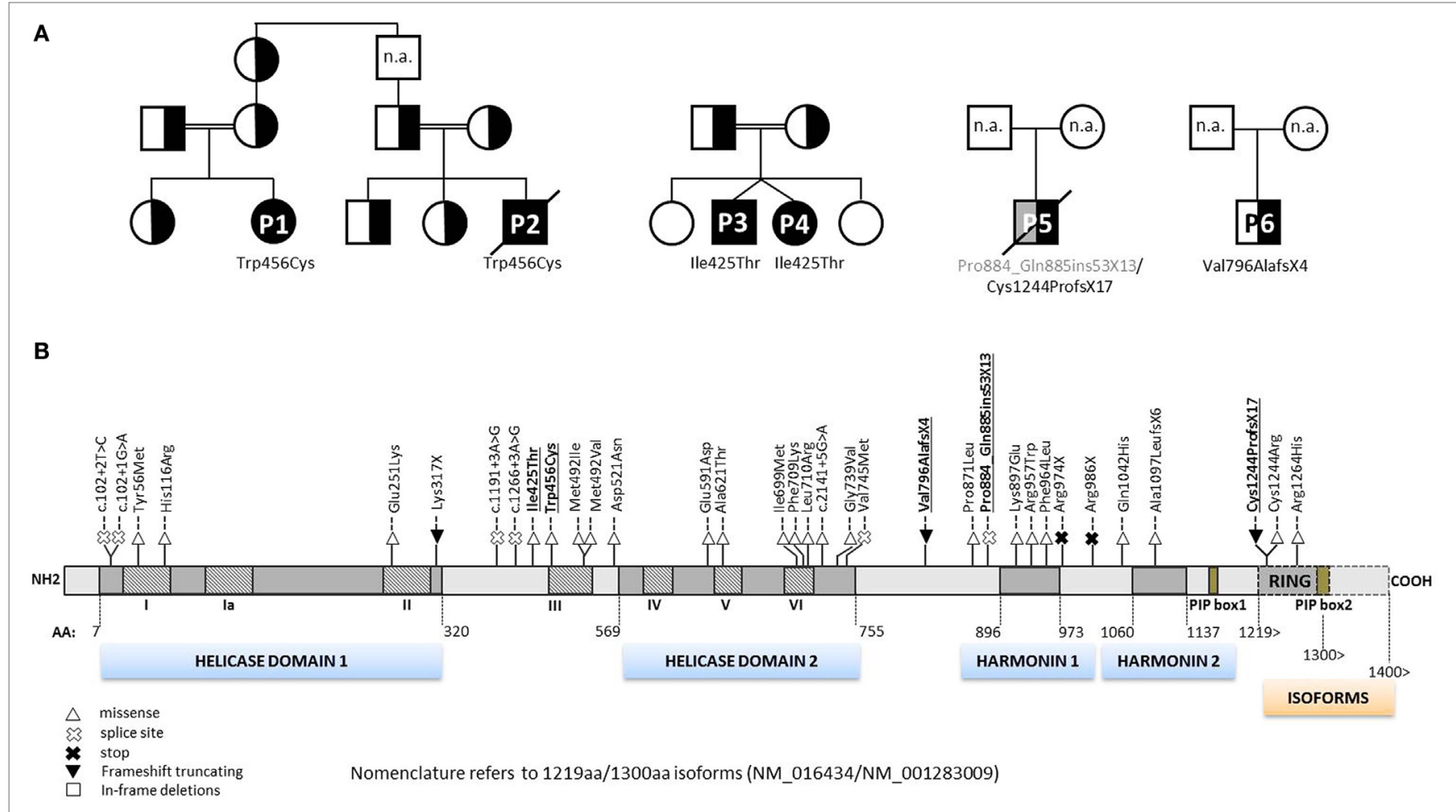

FIGURE 2 | Pedigrees of RTEL1-deficient patients and annotation of mutations. (A) Six RTEL1-deficient patients with their respective nuclear families are shown. P1 and P2 are part of a large consanguineous pedigree. P3 and P4 are twins. Heterozygous family carriers are indicated by half-filled symbols. P1-P4 carry homozygous missense mutations, P5 and P6 carry biallelic and monoallelic nonsense mutations, respectively. n.a., not analyzed. (B) The 1300aa RTEL1 isoform protein structure displaying the novel mutations described in this study (highlighted in bold, underlined font) along with previously reported mutations. Mutations previously reported using 1243aa isoform (NM_032957) in three reports (9, 10, 20) have been adapted to 1300aa isoform (NM_001283009). Heterozygous missense variants identified in association with pulmonary fibrosis (21-23) are not shown. For clarity, mutations are shown on protein level without "p." as preceding.

TABLE 3 | Characteristics of the segregating variants in P1 and P2.

\begin{tabular}{|c|c|c|c|c|c|c|c|c|c|c|}
\hline Gene & Position & Ref. & Obs. & Protein & Polyphen-2 & SIFT & CADD & ExAC allele counts & $\begin{array}{l}\text { ExAC } \\
\text { Z-score }\end{array}$ & $\begin{array}{c}\text { ExAC } \\
\text { pLI }\end{array}$ \\
\hline COL9A3 & $\begin{array}{l}\text { chr20 } 61451333 \\
\text { (rs142639450) }\end{array}$ & G & $A$ & $\begin{array}{l}\text { NM_001853 c.G308A } \\
\text { p.R103Q }\end{array}$ & 0.022 & 0.31 & 23.5 & $\begin{array}{l}\text { Het: 1748, hom: } 24 \text { (119804); } \\
\text { MAF: } 0.01459\end{array}$ & -1.09 & 0 \\
\hline HELZ2 & chr20 62196625 & G & $A$ & $\begin{array}{l}\text { NM_033405 c.G1843 } \\
\text { p.E615K }\end{array}$ & 0.809 & 0.84 & 0.002 & $\begin{array}{l}\text { Het: 78, hom: } 1 \text { (70806); } \\
\text { MAF: } 0.0011\end{array}$ & 0.25 & 0 \\
\hline RTEL1 & chr20 62319010 & G & $\mathrm{T}$ & $\begin{array}{l}\text { NM_016434 c.G1368T } \\
\text { p.W456C }\end{array}$ & 1.000 & 0 & 28.8 & Not observed & -1.71 & 0.78 \\
\hline
\end{tabular}

Prediction scores were calculated with Polyphen-2 (42), SIFT (43), and CADD (44). Variant counts (in brackets: total analyzed alleles) and frequencies were downloaded from ExAC database (45) (accession date 21 February 2017) for the whole population.

Ref., reference; Obs., observed; het, heterozygous; hom, homozygous; pLI, probability of loss of function intolerance.

1243aa isoform (NM_032957) that compared to other isoforms holds a longer exon5 (+24aa) was detected at very low levels using RT-PCR in peripheral blood MNCs of patients and controls, while it was absent in fibroblasts, pointing toward tissue-dependent specificity of alternative transcripts (Figure 4A). Furthermore, we noticed higher expression of long transcript (present in both $1300 \mathrm{aa} / 1400 \mathrm{aa}$ isoforms) in healthy MNC as compared to fibroblasts (Figure 4B). Finally, the longest 1400aa transcript was neither detectable in blood nor in fibroblasts using RT-PCR targeting exon 36 (not shown).

Both homozygous missense mutations identified in $\mathrm{P} 1-\mathrm{P} 4$ did not affect mRNA expression in RTEL1-deficient patient cells
(Figure 4B). As demonstrated by RT-PCR and cDNA sequencing, P5's RTEL1 c. $2652+5 \mathrm{G}>\mathrm{A}$ mutation abolishes the original donor splice site, resulting in transcription prolongation of exon 28 , adding 159 bp out of intron 28 (Figure 4C, left panel). A novel premature stop codon $(\mathrm{aa}+13)$ results in loss of the proliferating cell nuclear antigen-interacting protein PIP motif, RING domain, as well as recently identified harmonin-like domains (46). The mutated transcript showed similar mRNA expression signal to the wild-type allele. The second frameshift mutation in P5 was predicted to be protein truncating however did not affect mutant mRNA level as shown by cDNA sequencing (Figure $4 \mathrm{C}$, right panel). 


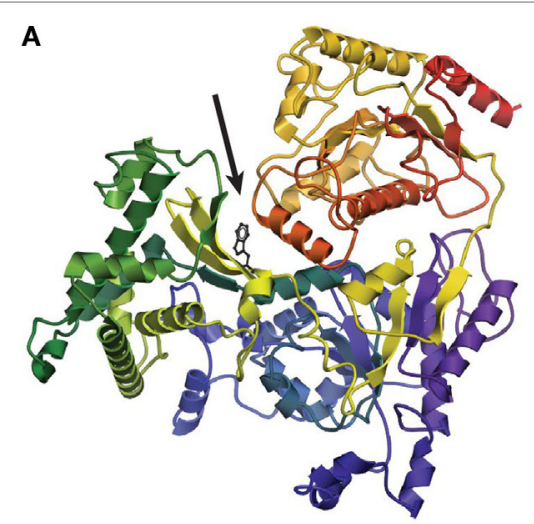

B

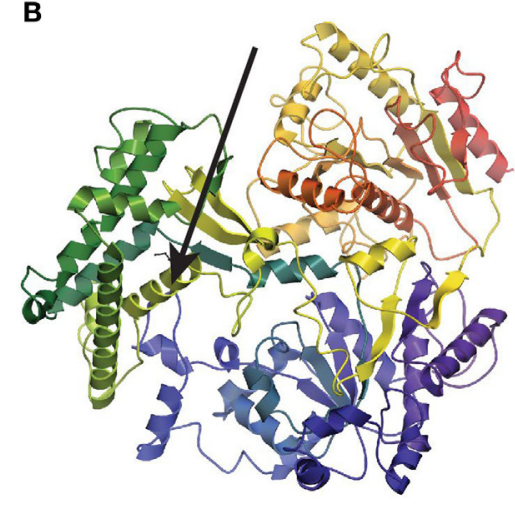

C

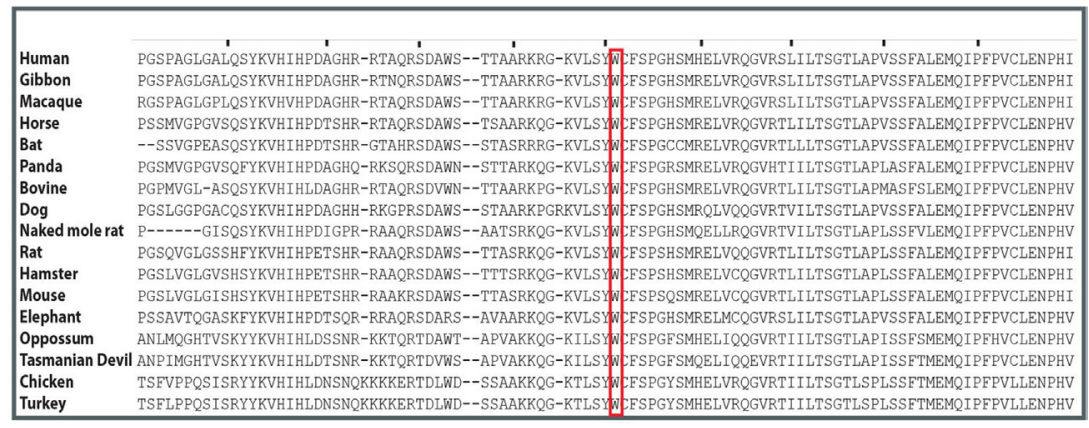

D

FIGURE 3 | Structure prediction and evolutionary conservation of RTEL1 mutations: p.Trp456Cys; p.lle425Thr. (A) The mutated aa (p.Trp456Cys) is predicted to be located in a $\beta$-strand in the linker between the two helicase domains (arrow) and is predicted to be buried. (B) The mutated aa ( $\mathrm{p}$.lle425Thr) is predicted to be located in $\alpha$-helix. Structure of RTEL1 amino acids (aa) 1 (blue) to 754 (red) was predicted by I-TASSER covering the two helicase domains and their linker based on the structure of 2vsfA (5). Secondary structures were assigned with the program ICM-Browser, Molsoft LLC. (C) Trp456 and (D) lle425 are highly conserved across 17 species.

\section{Severe Telomere Shortening and Premature Senescence in RTEL1 Deficiency}

Patients with RTEL1 deficiency exhibited very short telomeres (below the first percentile of age-matched controls) in $\mathrm{BM}, \mathrm{PB}$, and skin fibroblasts measured using $\mathrm{QPCR}$ and metaphase T/CFISH (Figures 5A,B). By contrast, parents of P1-P4 had normal telomere length (Figure 5B). To investigate if heterozygous carrier status affects telomere homeostasis under replicative stress, we investigated T-cell blasts of P1's parents. Upon long-term expansion, heterozygous RTEL1 $1^{\text {Trp456Cys }}$ lymphocytes exhibited significant telomere shortening (Figure 5C), while homozygous RTEL1 ${ }^{\text {Trp456Cys }}$ cells died prematurely (not shown). RTEL1deficient fibroblasts of P1 and P3 showed poor growth and premature cellular senescence (Figure 5D). T-cell phenotyping in $\mathrm{P} 3$ and $\mathrm{P} 4$ revealed that the majority of CD4 T-cells had a naïve phenotype, while almost $50 \%$ of CD8 T-cells were terminally differentiated effectors with senescent phenotype (Figure 5E), as determined by CD57 co-expression $(47,48)$. The proportion of $\mathrm{CD} 7^{+} \mathrm{T}$-cells increased over time in P3, despite absence of severe viral infections. Moreover, increased spontaneous apoptosis was observed in MNCs of P3 and P4 (Figure 5F). However, short-term proliferation, degranulation and effector cytokine production of T-cells were unaffected (Table 2).

\section{Homozygous RTEL1 Mutations Result in Genomic Instability}

Experimental evidence from studying RTEL1-deficient embryonic stem cells, C. elegans and human cell lines indicate that RTEL1 is required for maintaining genomic integrity and plays a key role in regulating homologous recombination (HR) (25-27). It is essential for the repair of mitotic and meiotic double strand breaks and its loss results in uncontrolled HR leading to chromosomal breakage. To test the functional effect of RTEL1 mutations on the genomic integrity in our patients, we investigated spontaneous and crosslinker-induced chromosomal damage (Figure 6). Chromosome preparations from fibroblasts of P1 showed elevated levels of chromatid/iso-chromatid rather than chromosome breaks and reunion figures (Figures 6A,D). End-to-end chromosome fusions were not observed. The spontaneous and MMC-induced G2 phase fractions of fibroblasts from P1 and P3 were significantly increased compared to normal controls $(P<0.001)$ (Figure 6E). By contrast, low dose of ionizing radiation $(1.5 \mathrm{~Gy})$ did not result in any abnormal findings 


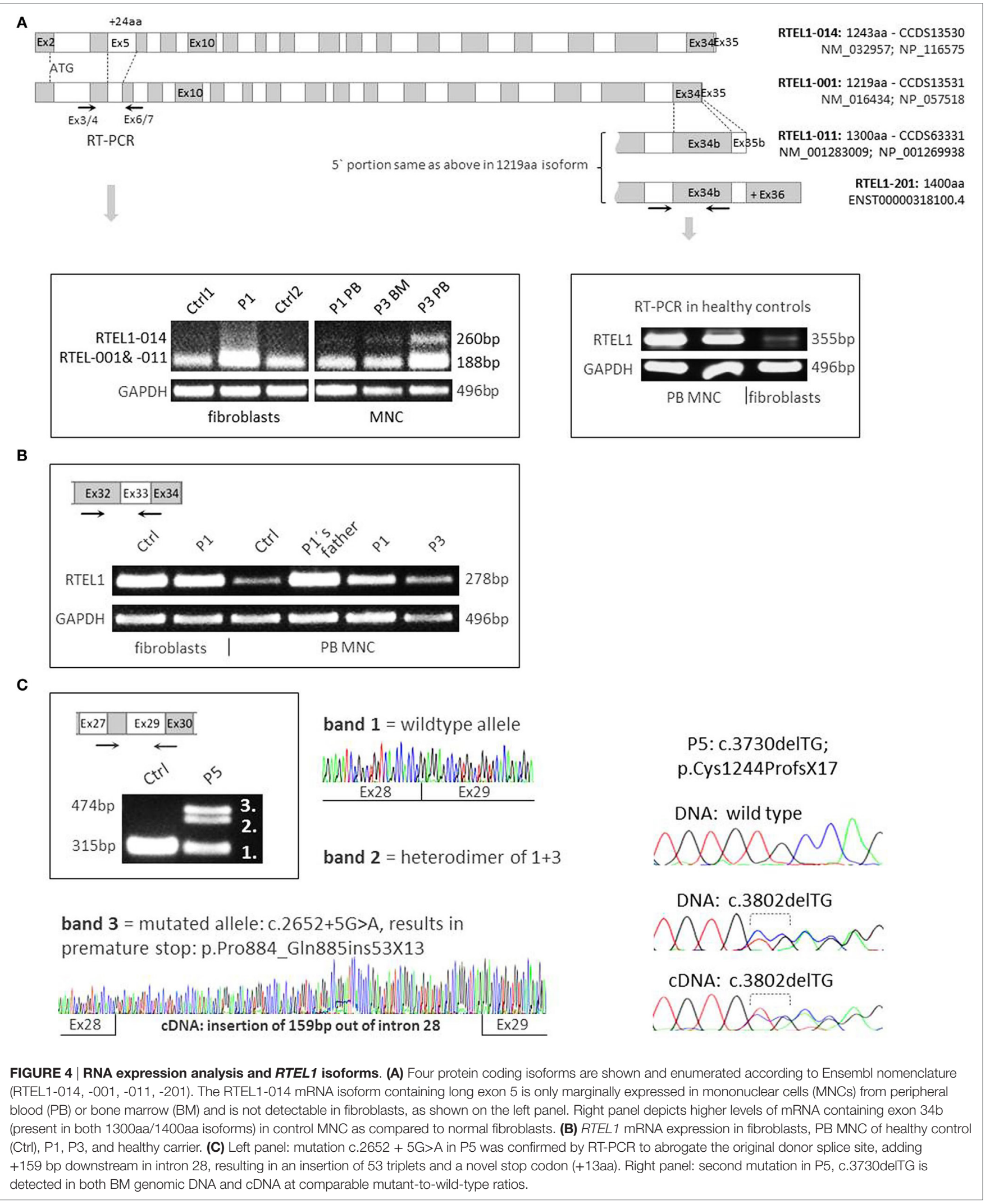


A

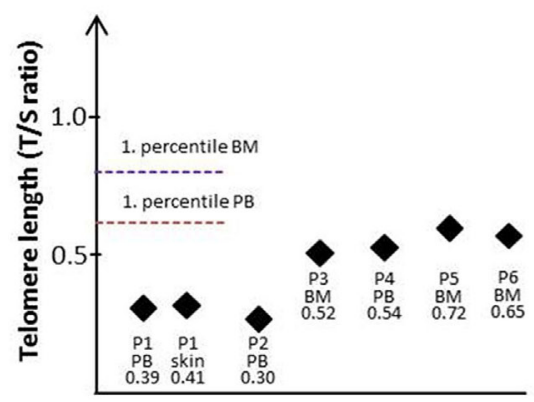

C

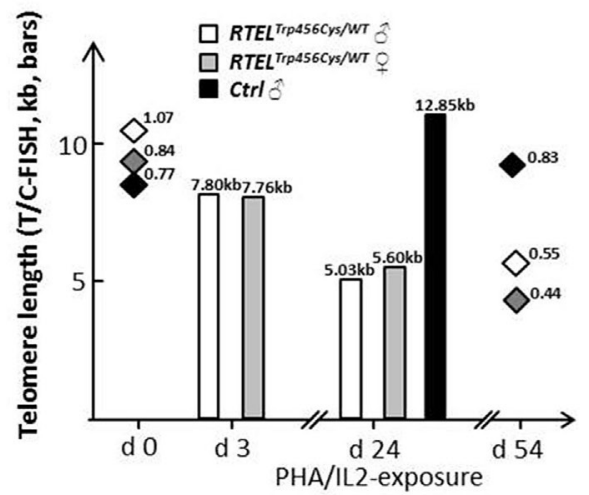

E

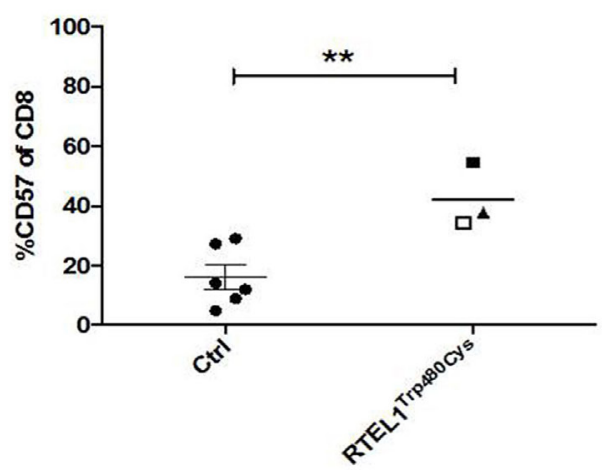

B

P 5: $5.80 \mathrm{~kb}$

norm $10.7+/-1.63 \mathrm{~kb}$

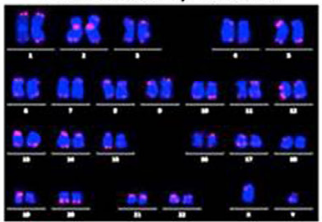

P 3: $6.16 \mathrm{~kb}$

norm $11.63+/-1.63 \mathrm{~kb}$

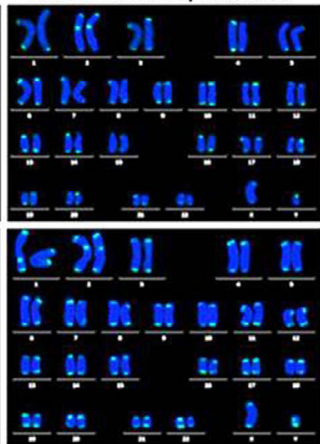

Father of P3: 10.06kb

norm $9.21+/-1.63 \mathrm{~kb}$

Mother of P3: 9.39k

norm $10.15+/-1.63 \mathrm{~kb}$
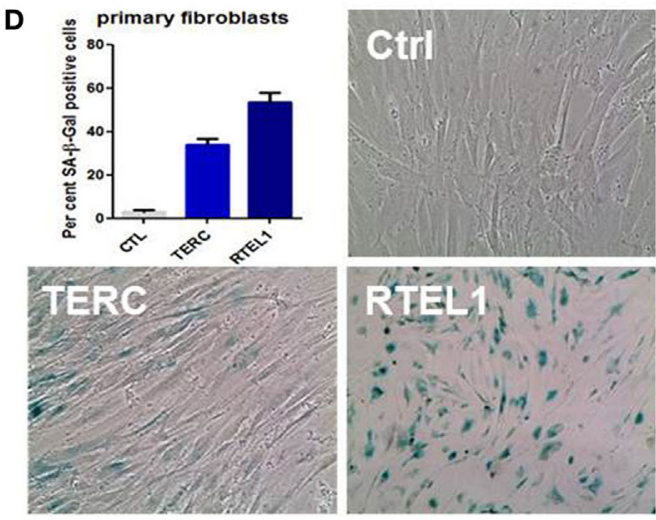

$\mathbf{F}$

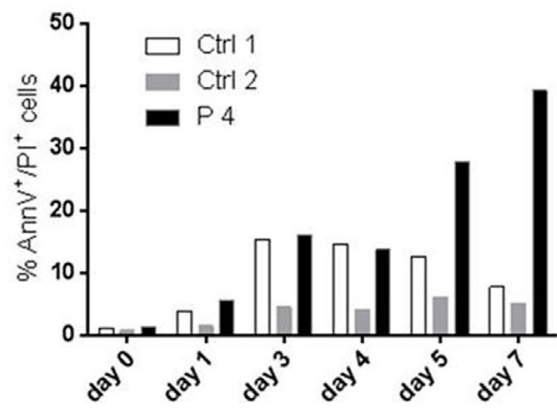

FIGURE 5 | Telomere shortening, senescence, and spontaneous apoptosis. (A) Relative telomere length (RTL) was measured using gPCR below the first percentile of healthy pediatric population ( $n=90$, age 2-18 years) in Peripheral blood, bone marrow and skin fibroblasts of patients P1-P6. Median of at least two independent triplicate measurements is shown. (B) Telomere/centromere metaphase FISH (T/C-FISH) confirms short telomeres in P5 and in P3 but not in heterozygous parents of P3/4. (C) Telomere shortening in Trp456Cys-heterozygous T-cells of parents of P1 after PHA/IL2-induced long-term expansion. Bars indicate absolute telomere length examined by T/C-FISH at days 3 and 24 of culture. In addition, RTL h (T/S-ratio by qPCR, diamonds) was investigated at days 0 and 54, confirming rapid telomere shortening observed using T/C-FISH results. (D) High rate of senescence visualized by $\beta$-galactosidase staining (blue) in RTEL1-deficient fibroblasts, compared to a healthy control and a patient with TERC mutation. The percentage of SA- $\beta$-Gal positive senescent cells is shown in the bar graph. (E) CD57 expression on CD8 cells of age-matched healthy controls (Ctrl) and RTEL1-deficient P3 at 4 years (open square) and 5 years of age (solid square) and P4 at 5 years of age (triangle). ${ }^{\star *} P$ value $<0.01$, calculated with a two-tailed $t$-test. (F) Increased spontaneous apoptosis in RTEL1-deficient peripheral blood mononuclear cell (PBMNC) of P4 after prolonged crude cell culture. Similar results were observed for P3 PBMNC (not shown). 


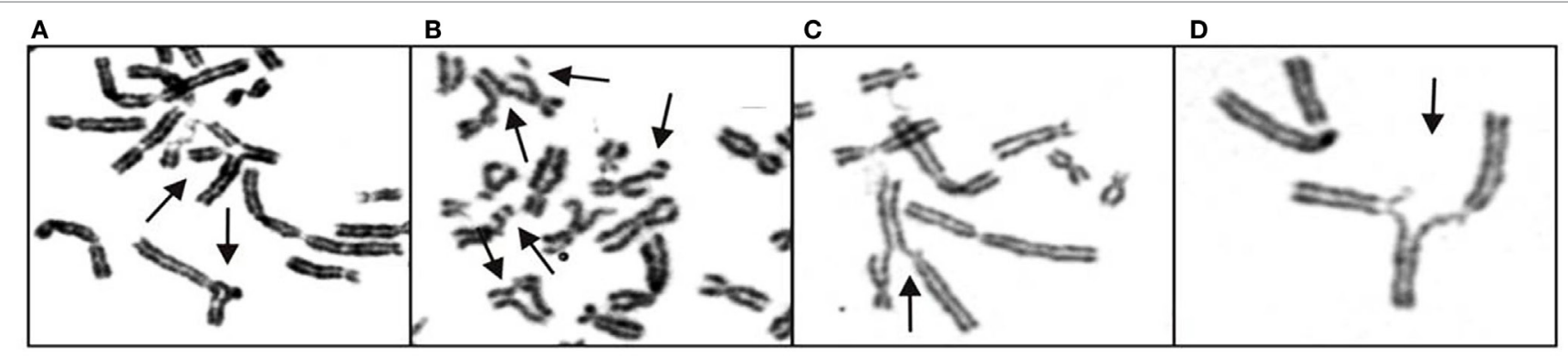

\begin{tabular}{|c|c|c|c|c|c|c|c|c|}
\hline \multirow[t]{3}{*}{$E$} & \multicolumn{8}{|c|}{ Proportion of G2 Phase Cells ${ }^{a}$} \\
\hline & \multicolumn{4}{|c|}{ w/o MMC } & \multicolumn{4}{|c|}{ w/ MMC } \\
\hline & Mean \pm SD & Range & $\mathbf{n}$ & Pvalue ${ }^{b}$ & Mean \pm SD & Range & n & Pvalue ${ }^{b}$ \\
\hline P1 & $19.0 \pm 4.11$ & $16.1-23.7$ & 3 & $<<0.001$ & $36.06 \pm 5.55$ & $31.3-42.2$ & 5 & $<<0.001$ \\
\hline P3 & $31.17 \pm 3.56$ & $27.2-34.1$ & 3 & $\ll 0.001$ & $43.57 \pm 3.68$ & $40.2-47.5$ & 3 & $\ll<0.001$ \\
\hline Ctrl & $8.05 \pm 3.78$ & $1.8-15.9$ & 50 & - & $13.9 \pm 4.74$ & $4.7-24.2$ & 49 & - \\
\hline FA & $11.25 \pm 5.07$ & $5.1-27.8$ & 25 & $<0.01$ & $43.10=10.05$ & $28.8-65.3$ & 25 & $\ll<0.001$ \\
\hline
\end{tabular}

$\mathbf{F}$

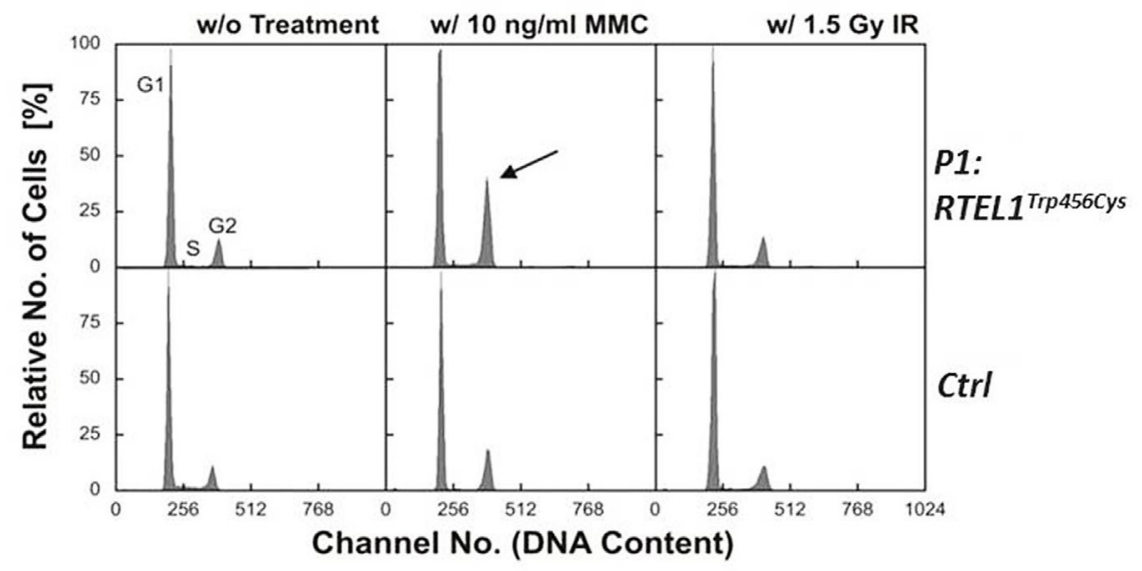

G

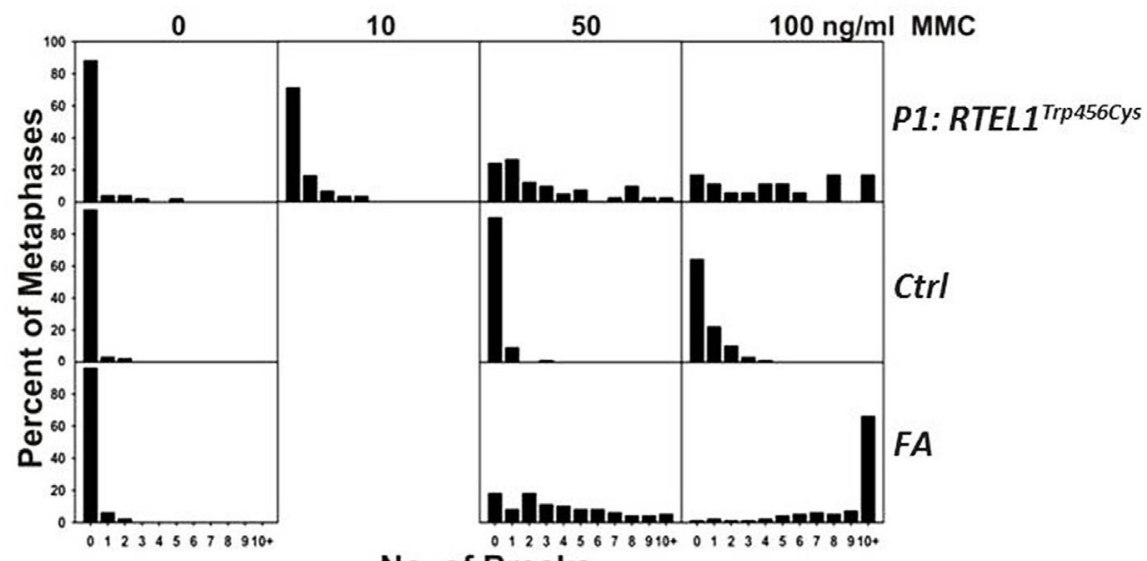

No. of Breaks

FIGURE 6 | Continued 
FIGURE 6 | Continued

Spontaneous chromosomal breakage and crosslink induced genomic instability. (A-D) Chromosomal aberrations in P1 fibroblasts exposed to 50 ng/ml mitomycin C (MMC), as indicated by arrows: (A) a multiradial and a triradial figure; (B) two atypical reunion figures as well as chromatid and chromosome breaks; (C,D) radial figures with chromatid breaks. (E) Spontaneous and MMC-induced G2 phase accumulation of RTEL1-deficient fibroblasts. Fibroblasts from healthy control (Ctrl) of Fanconi anemia patient (FA) run as controls. a DAPI stained cells from 48 h cultures w/o or w/10 ng/ml MMC; ${ }^{b}$ one-tailed Student's $t$-test, P1 or P3 compared with normal controls. (F) G2 phase accumulation of RTEL1-deficient fibroblasts of P1, DAPI staining. Compared to an untreated healthy control (G1 phase $72.5 \%$, S phase 15.9\%, G2 phase 11.6\%), fibroblasts from P1 spontaneously show an elevated G2 phase proportion (G1 phase $72.8 \%$, S phase 11.1\%, G2 phase 16.1\%; left panels). Exposure to $10 \mathrm{ng} / \mathrm{ml} \mathrm{MMC} \mathrm{increases} \mathrm{G2} \mathrm{phase} \mathrm{in} \mathrm{P1} \mathrm{disproportionately} \mathrm{(G1} \mathrm{phase} \mathrm{57.4 \% ,} \mathrm{S} \mathrm{phase} \mathrm{9.5 \% ,} \mathrm{G2} \mathrm{phase} \mathrm{33.1 \% ,} \mathrm{arrow)}$ compared to a control (G1 phase 69.6\%, S phase 7.5\%, G2 phase 22.9\%). By contrast, 1.5 Gy irradiation reveals comparable G2 phase fractions (P1: 16.0\%; control: 20.2\%; right panels; DAPI staining). (G) Chromosomal break distributions of RTEL1-deficient fibroblasts of P1. Fibroblasts were left untreated or exposed to MMC for the last $24 \mathrm{~h}$. Breakage rates amounted to 0.28 (0 MMC), 0.52 (10 ng/ml MMC), 2.71 (50 ng/ml MMC) or 4.72 (100 ng/ml MMC), respectively. These were elevated compared to normal control fibroblasts with breakage rates of 0.05 (0 MMC; normal mean, 0.02$), 0.12$ (50 ng/ml MMC; normal mean, 0.18 ), or 0.55 (100 ng/ml MMC; normal mean, 0.36); the normal mean rate for $10 \mathrm{ng} / \mathrm{ml}$ is 0.06 . Breakage rates of fibroblast P1 were more evenly distributed among all break classes and did not show the tendency toward metaphases with 10 or more breaks of FA fibroblasts at $100 \mathrm{ng} / \mathrm{ml} \mathrm{MMC}$.

(Figure 6F). Without treatment, we observed metaphases with three and five breaks, rarely ever seen in normal controls (Figure 6G). Unexpectedly, repeated chromosomal breakage analysis performed on hematopoietic cells from our patients yielded normal results (Table 1).

\section{Impaired Proliferative Capacity of B-Cell Precursors and BM Derived CD34+ Cells}

We had the opportunity to investigate the B-cell distribution in $\mathrm{BM}$ and blood of $\mathrm{P} 1$ at age 22 months during an acute adenovirus infection and after clearance 3 months later (Figures 7A-C). During acute infection, we observed a differentiation arrest at the level of pre-BI-progenitors, resulting in the absence of pre-BII-progenitors and immature B-cells; and correspondingly very low numbers of peripheral B-cells (Figure 7B). After clearance of infection all previously diminished B-cell populations normalized (Figure 7C). As the cellular immunity relies on continuous replenishment from hematopoietic stem cells (HSC), we additionally investigated the proliferative potential of primary RTEL1-deficient BM cells. While total BM and CD34 ${ }^{+}$cells of $\mathrm{P} 3$ and $\mathrm{P} 5$ failed to expand in vitro, after prolonged culture the CD34+ population nearly disappeared (Figures 7D,E).

\section{Unaffected V(D)J Recombination and T-Circle Accumulation in RTEL1 Deficiency}

The progressive B-cell lymphopenia is a frequent observation in the context of impaired somatic recombination, thus we also examined V(D)J recombination in RTEL1-deficient fibroblasts of $\mathrm{P} 1$. As depicted in Figure 8A, V(D)J recombination efficiency was unaffected and comparable to healthy controls. Based on recently published experimental data, RTEL1 has been proposed to dismantle T-loops during replication thus preventing catastrophic cleavage of telomeres as a whole extra-chromosomal T-circle (27). Surprisingly, we did not detect elevated T-circle formation in any of our patients or carriers (in fibroblasts, BM and PB) using rolling circle amplification assay when compared to RTEL1 null mouse cells and RTEL1-deficient human cells carrying the homozygous RTEL1 $1^{\text {Arg1264His }}$-mutation (Figure 8B), thus suggesting impaired T-loop disassembly may not be the only underlying cause of the disease.

\section{HSC Transplantation Corrects the Immunological and Hematological Phenotype of RTEL1 Deficiency}

Allogeneic HSCT was performed on P1 and P3 at 3.1 and 5.2 years, respectively. Both patients received non-manipulated BM after reduced intensity conditioning with fludarabine, thiotepa, and antithymocyte globulin. While P3 received BM from a 9/10 MUD, P1 was transplanted from the 48 years old HLA-identical grandmother who was healthy and had RTL within normal range. At HSCT, RTEL1 deficiency was not yet identified in the family and we were unaware of the donor's heterozygous state for the RTEL $1^{\text {Trp456Cys }}$-mutation. Full donor chimerism was achieved from day +22 onward and remained stable. At last follow-up (day $+1,530)$, P1 showed persisting hematological and immunological reconstitution. There were no signs of graft-versus-host-disease or chemotherapy-related toxicity. Chronic diarrhea improved with clearance of viral infections. Nonetheless, her esophageal stenosis persists over time and requires frequent dilatation to allow normal oral nutrition. Similar to other recently described DC patients $\mathrm{P} 1$ also developed multiple pulmonary arteriovenous malformations with need for continuous oxygen support (20). The course of HSCT in P3 was uneventful. Full donor chimerism was achieved from day +30 onward. At last follow-up at 2 years 6 months post HSCT the patient was 7 years 8 months old, showed good developmental progress and normal hematological and immunological function. His oral leukoplakia showed moderate progress but he did not show signs of esophageal stricture or other mucosal problems so far.

\section{DISCUSSION}

Dyskeratosis congenita represents a genetically heterogeneous group of disorders characterized by telomere shortening leading to BMF and mucocutaneous symptoms (1). Patients with HHS phenotype additionally suffer from cerebellar hypoplasia and immunodeficiency resulting in profound susceptibility for earlyonset systemic infections $(3,5)$. The latter can often be difficult to distinguish from primary defects of lymphocyte development such as severe combined immunodeficiencies (SCID) $(8,49)$. Immunophenotyping revealed a $\mathrm{T}^{+} \mathrm{B}^{-} \mathrm{NK}^{-}$phenotype in $\mathrm{P} 1-\mathrm{P} 5$, which in the context of pancytopenia pointed toward an inherited $\mathrm{BMF}$ syndrome. The normal percentage of circulating naïve T-cells 
A

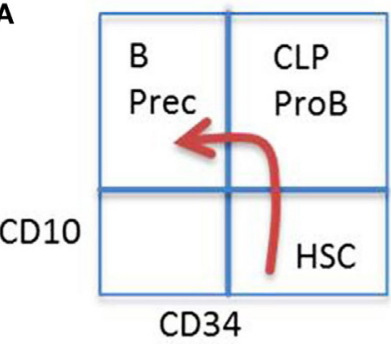

B

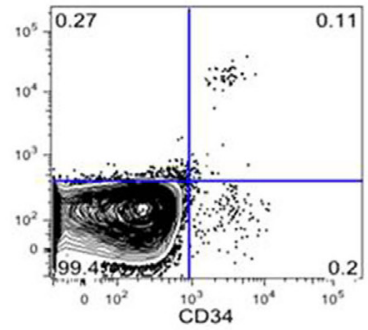

C
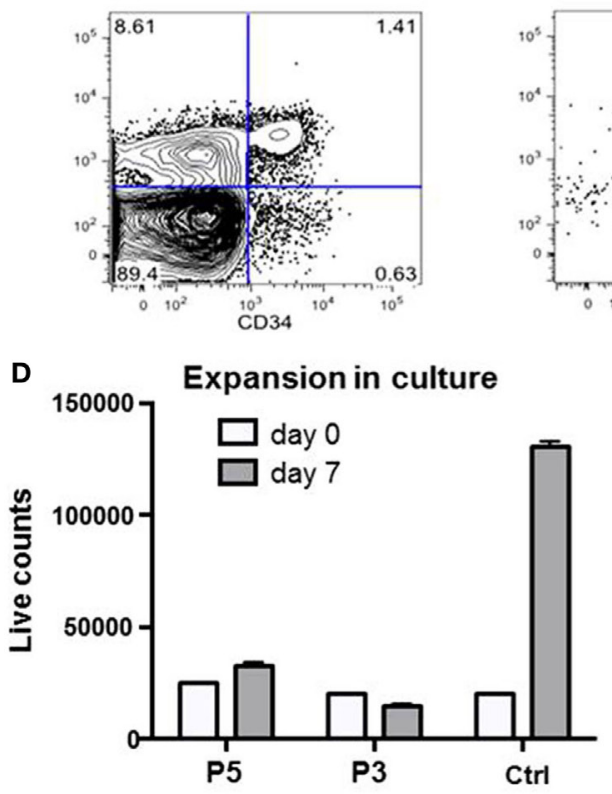
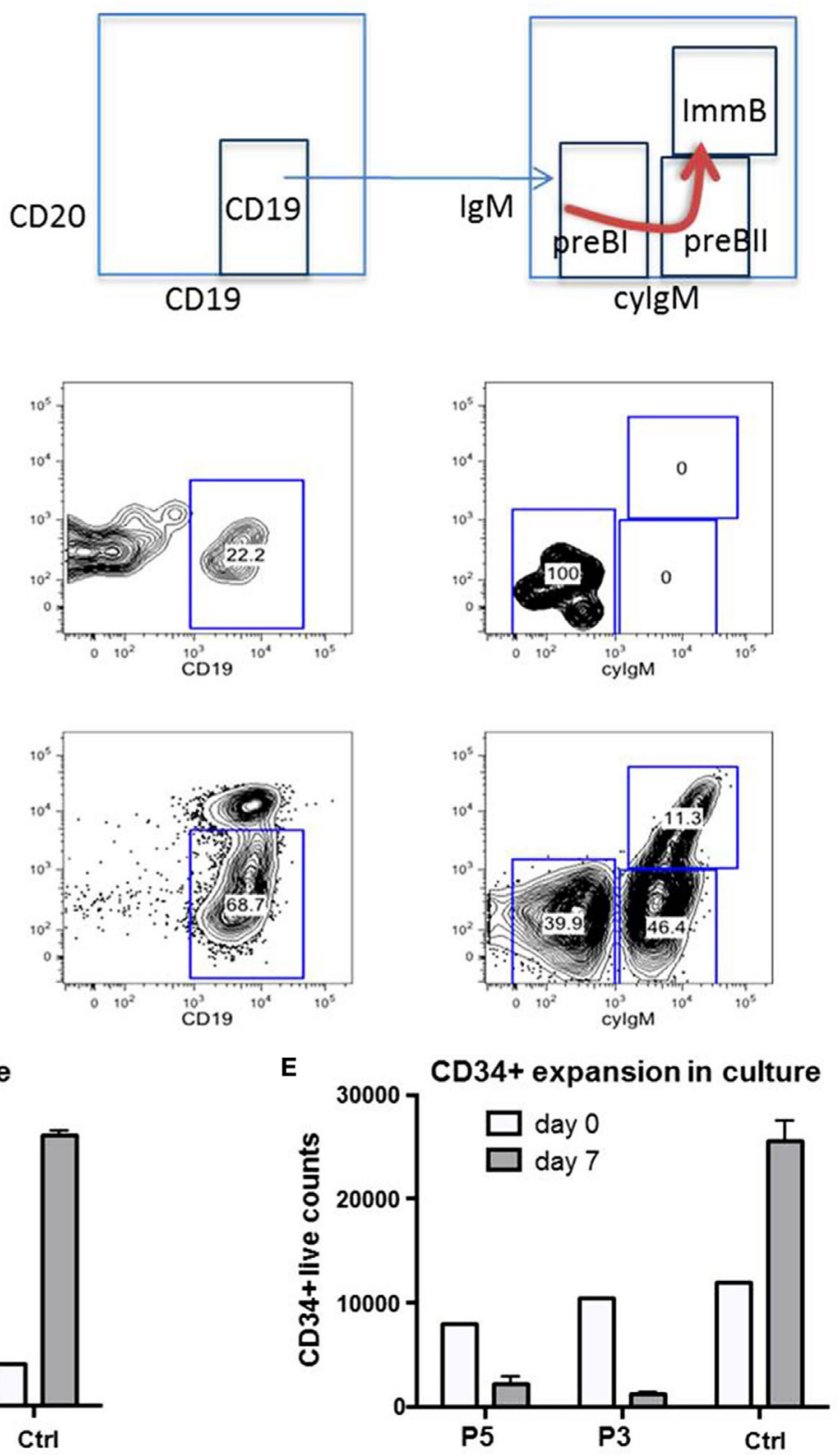

FIGURE 7 | Impaired proliferative capacity of B-cell progenitors in vivo and CD34+ cells in vitro. (A) Normal ontogeny of B-cells in bone marrow (BM). B Prec, B-cell precursors; CLP, common lymphoid progenitor; HSC, hematopoietic stem cells; ImmB, Immature B-cells. (B) B-cell differentiation is markedly impaired in BM of P1 during severe adenovirus infection. CLP/ProB subsets are greatly reduced while B cell precursors are missing. (C) Between infectious intervals, all populations recover. (D,E) Total and CD34+ selected HSC from P3 and P5 fail to expand in non-differentiating culture. Ctrl, healthy control.

suggested a regular thymic output in our patients. Furthermore, normal $\mathrm{V}(\mathrm{D}) \mathrm{J}$ recombination and lack of radiosensitivity argued against an initially assumed $\mathrm{B}^{-} \mathrm{NK}^{-}$SCID in index patient $\mathrm{P} 1$. ES of the index family identified homozygous mutation in the DNAhelicase gene RTEL1 as the molecular cause of disease. Biallelic RTEL1 mutations had been identified as the molecular basis in a subset of patients with HHS (9-13). Overall, we found two novel homozygous missense mutations in $\mathrm{P} 1-\mathrm{P} 4$ and three novel truncating mutations in P5 and P6. Homozygous mutations in our patients correlated with onset of symptoms within the first 3 years of life and faster disease dynamics. By contrast, in P5 with biallelic truncating mutations, relevant hematologic problems developed in the second decade of life and were apparently precipitated by an EBV infection. Finally, P6 with only one truncating mutation was identified following a work-up for thrombocytopenia and macrocytosis seen in a routine blood count prior to orthopedic surgery at 17 years of age.

By comparison, the reported mutational landscape for RTEL1 deficiency shows a tendency of clustering at helicase domain 2 and between/at harmonin 1 and 2 (Figure 2B). These mutations, identified in 24 pedigrees with DC are mostly compound heterozygous and in the majority of those cases there is at least 
A

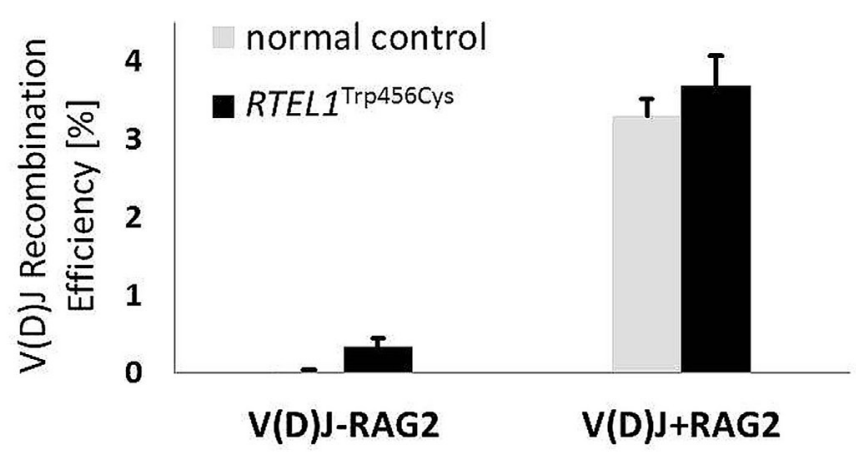

B
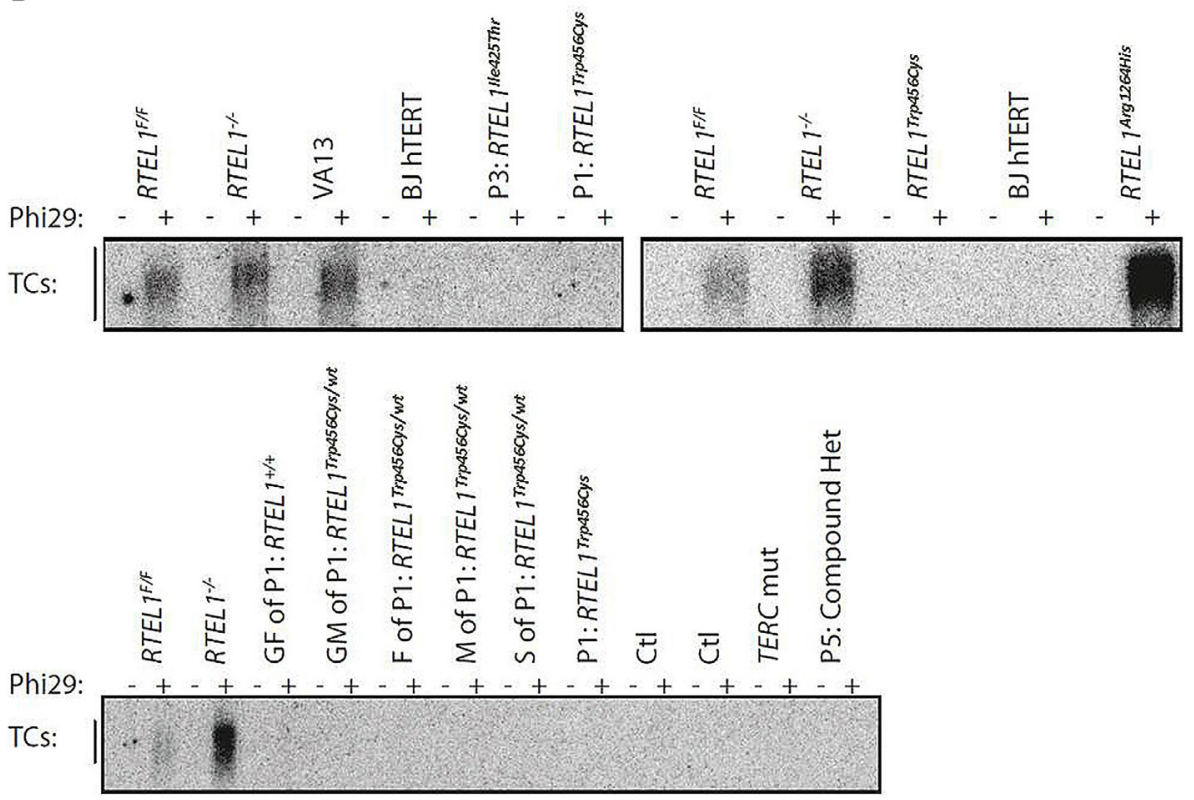

FIGURE 8 | Unaffected V(D)J recombination and T-circle formation. (A) V(D)J recombination rate in RTEL1-deficient fibroblasts of P1 is comparable to a healthy control. V(D)J-RAG2, RAG1 vector alone; V(D)J + RAG2, RAG1 and RAG2 vectors combined. (B) Phi29-dependent telomeric circle (T-circle) amplification assay. Top left: fibroblasts of P1 (p.Trp456Cys) and P3 (p.lle425Thr) as compared to VA13 ALT cells (a human lung fibroblast cell line that maintains telomeres in the absence of telomerase and accumulates free TC). RTEL1-deficient mouse embryonic fibroblasts (MEFs) were used as positive controls and Rte/1-/- floxed (F/F) MEFs, and BJhTERT (hTERT immortalized human foreskin fibroblast cell line) as negative controls. Top right: TC accumulation in cells of a patient with a homozygous RTEL1 mutation p.Arg1264His (previously reported) in comparison to undetectable TC in P1 (p.Trp456Cys). Bottom: TC amplification assay in T-lymphoblasts of P1 and family members (GF, grandfather; GM, grandmother; F, father; M, mother; S, sister), healthy controls (Ctl), a patient with confirmed mutation in TERC, and P5 with a compound heterozygous RTEL1 mutation. T-lymphoblasts were expanded from total peripheral blood mononuclear cell using PHA (lanes 5-18) or anti-CD3/28 beads (lanes 19-24). Phi29, Phi29 DNA polymerase; Rte/1F/F, Rtel1 floxed MEFs before Cre-mediated excision of the Flox alleles; Rtel1-/-, Rtel1-deficient MEFs after Cre-mediated excision of the Flox alleles. Wt, wild type.

one nonsense truncating mutation per case (similar to P5). The rare exception are homozygous RTEL $1^{\text {Phe964Leu }}$ and RTEL $1^{\text {Arg1264His }}$ mutations located at C-terminus $(10,13,14)$. By contrast, homozygous RTEL $1^{\text {Ile425Thr }}$ and RTEL $1^{\text {Trp456Cys }}$-mutations reported here reside closer to $\mathrm{N}$-terminus, in between two functional helicase domains.

Based on the results from cellular and animal models, RTEL1 is essential for DNA replication, and plays a key role in HR and telomere maintenance. In agreement with recent reports, we here show that very short telomeres in various primary tissues, and chromosomal breakage in fibroblasts represent the cellular phenotype of human RTEL1 deficiency (Table 4). It remains to be answered why the genomic instability is restricted to fibroblasts but not hematopoietic cells of RTEL1-deficient patients. One potential explanation might be the tissue-dependent expression of various RTEL1 isoforms with their specific functionality. Supporting this, we show that different isoforms are expressed at uneven levels in fibroblasts and hematopoietic cells. Our experimental findings on genomic instability reflect a DNA repair disorder of inter-strand crosslinks. The spontaneous G2 phase accumulation and chromosomal aberrations, and pronounced MMC-induced G2 phase arrest of RTEL1-deficient fibroblasts resemble the phenotype of Fanconi anemia fibroblasts of most subtypes. Thus far, genomic instability had not been considered a defining feature in DC, but notably, Dokal and colleagues previously reported spontaneous chromosomal rearrangements in 
TABLE 4 | Phenotype of RTEL1 deficiency in mouse and human.

\begin{tabular}{|c|c|c|}
\hline & Mouse & Human \\
\hline \multirow[t]{2}{*}{ Genetic background and disease severity } & Rtel/-/- embryonic lethal & $\begin{array}{l}\text { - Compound heterozygous: DC/HHS (24 patients/18 families) } \\
\text { - Homozygous missense: p.Phe964Leu, p.Arg1264His mutations in DC/ } \\
\text { HHS (4 patients/3 families), NK cell deficiency (1 patient) }\end{array}$ \\
\hline & 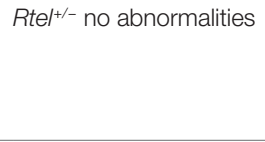 & $\begin{array}{l}\text { - Heterozygous nonsense: hypocellular BMF, DC/HHS (2 patients/1 } \\
\text { family), lung fibrosis ( } 9 \text { patients/6 families) } \\
\text { - Heterozygous missense: thus far only in DC-like disease (1 patient) and } \\
\text { pulmonary fibrosis (14 patients/10 families) }\end{array}$ \\
\hline Radiosensitivity & No: MEFs Rtel/-- & No \\
\hline Crosslinker sensitivity (MMC-induced) & Yes: MEFs Rtel//- & $\begin{array}{l}\text { Yes: fibroblasts } \\
\text { No: PB }\end{array}$ \\
\hline Chromosomal instability (spontaneous) & Yes: ES Rtel/- & $\begin{array}{l}\text { Yes: fibroblasts } \\
\text { No: PB }\end{array}$ \\
\hline Telomere shortening & Yes: ES Rtel/-- & Yes: fibroblasts and PB/bone marrow \\
\hline BMF and immune deficiency & n.a. (lethal) & Yes: BMF and T+B-NK- phenotype \\
\hline Cancer predisposition & n.a. (lethal) & Unknown, so far not reported ${ }^{d}$ \\
\hline
\end{tabular}

MEFs, mouse embryonic fibroblasts; ES, embryonic stem cells; MMC, mitomycin C; n.a., data not available; +/-, heterozygous; -/-, homozygous; DC, dyskeratosis congenita;

HHS, Hoyeraal-Hreidarson syndrome; BMF, bone marrow failure; PB, peripheral blood.

${ }^{a}$ Recently, homozygous missense mutation, p.Arg1264His (14) was reported in a 23-month-old girl born with isolated natural killer cell deficiency.

'So far, only one heterozygous nonsense mutation p.Arg986X (9) was reported in two brothers with severe DC and their healthy mother, in addition to P6 reported here.

'Ballew et al. (13) reported a heterozygous mutation p.Ala621Thr (equals p.Ala645Thr in NM_032957 isoform) in a patient with BMF and short telomeres; Deng et al. (12) reported

on a lung fibrosis in an otherwise healthy family member with heterozygous mutation (p.Met492lle). Similarly, Newton et al. (21) and Kannengiesser et al. (22) reported pulmonary

fibrosis in 11 patients in 5 families (mutations: p.Pro484Leu, p.Pro647Leu, p.Ser688Cys, p. His1124Pro, p.Tyr49Met, p.Arg213Trp, and p.Phe964Leu); Stuart et al. (23) also

demonstrated three patients with pulmonary fibrosis and short telomeres harboring heterozygous missense variants p.Pro484Leu, p.Pro647Leu, and p. His 1124 Pro.

'Several studies demonstrated an association between RTEL1 rs2297440, rs6010620, and rs6062299 polymorphisms and the risk of glioma (53).

DC-fibroblasts (50). Moreover mouse Rtel1 ${ }^{-/-}$embryonic stem cells displayed many chromosome breaks and fusions upon differentiation in vitro (Table 4) (51). Nevertheless, it is too early to speculate whether, in analogy to genomic instability syndromes, RTEL1 deficiency might be associated with an increased cancer predisposition manifesting later in life. Interestingly, the analysis of mice with deficient RTEL1-PCNA interaction revealed accelerated onset of tumorigenesis in a $p 53^{-/-}$background (52). However, the clinical histories of all our families and the published data do not support the notion of increased tumor risk. Yet, it is rather difficult to assess cancer predisposition in patients succumbing early in life or when RTEL1 deficiency does not affect global genome integrity. Finally, it is evident that the clinical penetrance is higher and onset much earlier for immunodeficiency, and BMF as opposed to potential tumor susceptibility.

T-loop disassembly during replication has been reported as one of the chief functions of RTEL1 (10). This prevents catastrophic cleavage of telomeres as whole T-circles by the SLX4 complex, facilitating the physiological replication of telomeric repeats. Of note, T-circle accumulation was not observed in primary fibroblasts or T cells of our patients with mutations p.Trp456Cys, p.Ile425Thr, p.Pro884_GIn885ins53X13, and p.Cys1244ProfsX17 unlike in recently reported patients with biallelic RTEL1 mutations (homozygous p.Arg1264His; compound heterozygous p.Leu710Arg/p.Lys897Glu and p.del398_422/p.Arg957Trp) which exhibited substantial T-circle accumulation $(10,13)$. However, the results of our study are in line with observations made by Deng et al. who also have not identified increased $\mathrm{T}$-circle formation in patient cells with compound heterozygous mutations p.Met492Ile/p.Arg974X (12). In conclusion, it is possible that mutations abolishing the PIP-boxes and thus the
RTEL1-PCNA interaction do not result in T-circle formation, as recently reported for the PIP-mutant mouse $(12,52)$. The mutations characterized by us possibly do not affect regions necessary for T-loop disassembly and the suppression of telomere loss as a whole circle.

We demonstrate a marked vulnerability of RTEL1-deficient cells to replicative stress in vivo and in vitro. This is in analogy to findings revealing that RTEL1 is indispensable for replication by associating with the replisome and promoting normal genome replication (52). Systemic infections demand for a high replicative turnover, which is markedly limited in RTEL1 deficiency. This is reflected by the insufficient B-cell lineage proliferation, as well as expansion incapability and premature apoptosis of CD $34^{+}$cells of our patients. It is expected that RTEL1-deficient HSC lose their self-renewal capacity due to impaired telomere replication and cell proliferation, ultimately resulting in proliferative exhaustion of the HSC compartment and progressive $\mathrm{BMF}$. Consequently, the numbers of B-cell precursors diminish over time, leading to hypogammaglobulinemia and loss of specific antibodies in some of our patients. Overall, the replicative capacity seems to be severely limited even in the absence of infectious replicative stimuli. This notion is supported by the observation of premature senescence in fibroblasts and T-cells, in addition to the increased spontaneous apoptosis of RTEL1deficient MNCs in vitro-a mechanism which may expectedly result in a progressive loss of immune cells in vivo. Classic tests to evaluate for T-cell effector functions (i.e., short-term proliferation, degranulation, and effector cytokine production) delivered normal results in RTEL1-deficient patients. However, T-cells of heterozygous carriers demonstrated a significant telomere shortening upon mitogen-induced long-term proliferation while 
homozygous cells die prematurely. We therefore assume that the observed susceptibility to viral disease in RTEL1 deficiency and likely in other DC-subtypes may be a consequence of T-cell exhaustion upon repeated proliferation stimuli triggered by infections. In addition, loss of effector T-cells due to BMF and/ or premature senescence as suggested in adult DC patients (49) may have further contributed to secondary T-cell deficiency in our patients.

Several observations indicate that although heterozygous RTEL1 mutations can facilitate telomere shortening, their pathogenic effect can be compensated by the functional wild-type allele in vivo, as opposed to biallelic mutations which result in severe clinical phenotype. First, the missense heterozygotes described in our study were clinically healthy, had normal telomere length, and did not show signs of anticipation. Missense heterozygous RTEL1 mutations reported thus far did not result in DC phenotype despite telomere shortening in some of the carriers, with the exception of p.Ala621Thr in one patient with DC-like phenotype (Figure 2B; Table 4) as reported by Ballew et al. (9). Notably, majority of the cases reported with solely heterozygous RTEL1 mutations are found to be associated with telomeropathy-related lung fibrosis (21) and familial pulmonary fibrosis (22, 23) with no immunologic or hematologic phenotypes (Table 4). Second, favorable HSCT outcome with no signs of graft failure more than 4 years after HSCT in P1, who was transplanted from a heterozygous mutation carrier, suggests that certain missense RTEL1 mutations in heterozygous state may not affect the HSC capacity. However, given the observation that the HSCT procedure itself results in telomere loss corresponding to telomere aging of roughly 15 years cautious long-term monitoring of engraftment is warranted in P1. It should be noted that transplantation from clinically silent heterozygous family member is generally not recommended in DC $(54,55)$.

The classical mucocutaneous triad pinpointing toward DC (leukoplakia, dystrophic nails, and reticular pigmentation) may be completely missing or only partially present even years after onset of BMF and immunodeficiency in RTEL1-deficient patients. Determination of telomere length could therefore be considered a first-line diagnostic procedure in early-onset immunodeficiency with $\mathrm{T}^{+} \mathrm{B}^{-} \mathrm{NK}^{-}$phenotype, particularly when associated with hypocellular BMF. Initially, BMF may only be transient and/or associated with systemic infections.

Therapeutic options are limited in RTEL1-deficient patients. Although androgens can fairly improve blood counts they do not ameliorate the infectious complications. While HSCT offers a potential cure for all BMF-associated symptoms, it also reveals a decision conflict in DC patients. Non-hematological complications (e.g., mucosal fragility and lung fibrosis) are not accessible and may be even aggravated by the procedure itself. However, HSCT can ultimately improve the clinical outcome and the quality of life and may therefore be considered in patients with life-threatening immunodeficiency and BMF. Whether HSCT prevents or increases the risks for tumorigenesis in RTEL1 deficiency remains unanswered at present. Since chemotherapyrelated toxicity is excessive in DC independently of the genetic cause, it is obvious that reduced intensity preparative regimens are warranted. In our patients, genomic instability was observed in fibroblasts but not in hematopoietic cells. Nevertheless, alkylating DNA-crosslinking drugs such as busulfan, platins, nitrosoureas, and nitrogen mustards (i.e., cyclophosphamide, melphalan) might have to be considered with caution. Finally, we observe stable hematopoiesis without signs of replicative exhaustion in P1 after HSCT from a family donor with heterozygous RTEL1 missense mutation. Nevertheless, given the short follow-up observation of 4 years, and in line with previous reports of unfavorable HSCT outcome in a situation with family donor who is DC mutation carrier, the present data are too limited to support HSCT from silent RTEL1 mutation carriers.

\section{ETHICS STATEMENT}

Written informed consent was obtained prior to inclusion of patients. The studies were approved by the institutional review board of the University Hospital Freiburg: protocol number CCI-282/11, studies EWOG-MDS 98 (\#NCT00047268) and 2006 (\#NCT00662090). The protocol was approved by the local Ethics Committees (CPMP/ICH/135/95 and 430/16).

\section{AUTHOR CONTRIBUTIONS}

CS, MWW, SS, and KB designed the study and prepared the manuscript; SS, MR, SH, NS, J-BV, GG, KT, ND, UP, AR-E, EkL, and CJ performed experiments; $\mathrm{AK}, \mathrm{MH}, \mathrm{JA}, \mathrm{HH}, \mathrm{WW}, \mathrm{GE}, \mathrm{EcL}$, $\mathrm{LR}$, and BS cared for patients and contributed the clinical data; SB designed and coordinated the T-loop studies and gave conceptual advice; MS performed histological studies; KS designed the V(D)J studies and analyzed data; DS designed the chromosomal breakage studies and analyzed data; SE and CN gave conceptual advice and participated in data analyses, and manuscript writing.

\section{ACKNOWLEDGMENTS}

The authors would like to thank Uli Salzer and Sebastian Fuchs for immunological analyses; Marena Niewisch, Michael Schmitz, Alfred Reiter, and Frank Berthold for clinical data; Anette Schmitt-Gräff for histology studies; Alexandra Fischer and EvaMaria Rump for data and sample management; Gunda Ruzaike and Sandra Urbaniak for technical assistance; and John H. J. Petrini for providing cells with RTEL1 Arg1264His mutation to the Boulton lab.

\section{FUNDING}

This work was supported by the Deutsche Krebshilfe Max Eder Grant (109005) and BMBF grant (01GM1301) to MWW, German Federal Ministry of Education and Research (DKTK German cancer consortium, molecular diagnostics of pediatric malignancies) to MWW and CN; the Austrian Science Fund (FWF): START Program Project Y595-B13, Jeffrey Modell Foundation Translational Research Program grant, the ERC under the European Union's Seventh Framework Program (FP7/20072013)/ERC grant agreement no. 310857 (all to KB); The ELITE 
program (Baden Württemberg Stiftung) to MR and the German Federal Ministry of Education and Research (BMBF 01 EO 0803 grant to the Center of Chronic Immunodeficiency and BMBF 01GM1517C grant to the PID-Net Initiative subproject A3 to CS).

\section{REFERENCES}

1. Dokal I. Dyskeratosis congenita. Hematology Am Soc Hematol Educ Program (2011) 2011:480-6. doi:10.1182/asheducation-2011.1.480

2. Alter BP. Diagnosis, genetics, and management of inherited bone marrow failure syndromes. Hematology Am Soc Hematol Educ Program (2007):29-39. doi:10.1182/asheducation-2007.1.29

3. Calado RT, Young NS. Telomere diseases. N Engl J Med (2009) 361(24): 2353-65. doi:10.1056/NEJMra0903373

4. Alter BP, Rosenberg PS, Giri N, Baerlocher GM, Lansdorp PM, Savage SA. Telomere length is associated with disease severity and declines with age in dyskeratosis congenita. Haematologica (2012) 97(3):353-9. doi:10.3324/ haematol.2011.055269

5. Hoyeraal HM, Lamvik J, Moe PJ. Congenital hypoplastic thrombocytopenia and cerebral malformations in two brothers. Acta Paediatr Scand (1970) 59(2):185-91. doi:10.1111/j.1651-2227.1970.tb08986.x

6. Hreidarsson S, Kristjansson K, Johannesson G, Johannsson JH. A syndrome of progressive pancytopenia with microcephaly, cerebellar hypoplasia and growth failure. Acta Paediatr Scand (1988) 77(5):773-5. doi:10.1111/j.16512227.1988.tb10751.x

7. Touzot F, Gaillard L, Vasquez N, Le GT, Bertrand Y, Bourhis J, et al. Heterogeneous telomere defects in patients with severe forms of dyskeratosis congenita. J Allergy Clin Immunol (2012) 129(2):473-2, 482.e1-3. doi:10.1016/ j.jaci.2011.09.043

8. Jyonouchi S, Forbes L, Ruchelli E, Sullivan KE. Dyskeratosis congenita: a combined immunodeficiency with broad clinical spectrum - a single-center pediatric experience. Pediatr Allergy Immunol (2011) 22(3):313-9. doi:10.1111/j. 1399-3038.2010.01136.x

9. Ballew BJ, Yeager M, Jacobs K, Giri N, Boland J, Burdett L, et al. Germline mutations of regulator of telomere elongation helicase 1, RTEL1, in dyskeratosis congenita. Hum Genet (2013) 132(4):473-80. doi:10.1007/s00439013-1265-8

10. Walne AJ, Vulliamy T, Kirwan M, Plagnol V, Dokal I. Constitutional mutations in RTEL1 cause severe dyskeratosis congenita. Am J Hum Genet (2013) 92(3):448-53. doi:10.1016/j.ajhg.2013.02.001

11. Le Guen T, Jullien L, Touzot F, Schertzer M, Gaillard L, Perderiset M, et al. Human RTEL1 deficiency causes Hoyeraal-Hreidarsson syndrome with short telomeres and genome instability. Hum Mol Genet (2013) 22(16):3239-49. doi: $10.1093 / \mathrm{hmg} / \mathrm{ddt} 178$

12. Deng Z, Glousker G, Molczan A, Fox AJ, Lamm N, Dheekollu J, et al. Inherited mutations in the helicase RTEL1 cause telomere dysfunction and HoyeraalHreidarsson syndrome. Proc Natl Acad Sci U S A (2013) 110:E3408-16. doi:10.1073/pnas.1300600110

13. Ballew BJ, Joseph V, De S, Sarek G, Vannier JB, Stracker T, et al. A recessive founder mutation in regulator of telomere elongation helicase 1, RTEL1, underlies severe immunodeficiency and features of Hoyeraal Hreidarsson syndrome. PLoS Genet (2013) 9(8):e1003695. doi:10.1371/journal.pgen.1003695

14. Hanna S, Beziat V, Jouanguy E, Casanova JL, Etzioni A. A homozygous mutation of RTEL1 in a child presenting with an apparently isolated natural killer cell deficiency. J Allergy Clin Immunol (2015) 136(4):1113-4. doi:10.1016/j. jaci.2015.04.021

15. Keel SB, Scott A, Sanchez-Bonilla M, Ho PA, Gulsuner S, Pritchard CC, et al. Genetic features of myelodysplastic syndrome and aplastic anemia in pediatric and young adult patients. Haematologica (2016) 101(11):1343-50. doi:10.3324/ haematol.2016.149476

16. Moriya K, Niizuma H, Rikiishi T, Yamaguchi H, Sasahara Y, Kure S. Novel compound heterozygous RTELl gene mutations in a patient with Hoyeraal-Hreidarsson syndrome. Pediatr Blood Cancer (2016) 63(9):1683-4. doi: $10.1002 / \mathrm{pbc} .26030$

17. Jullien L, Kannengiesser C, Kermasson L, Cormier-Daire V, Leblanc T, Soulier J, et al. Mutations of the RTEL1 helicase in a Hoyeraal-Hreidarsson syndrome
The lab of SB is funded by Cancer Research UK and by an ERC Advanced Investigator Grant (RecMitMei). SB is a recipient of a Royal Society Wolfson Research Merit Award. J-BV is funded by a long-term fellowship from ERC. patient highlight the importance of the ARCH domain. Hum Mutat (2016) 37(5):469-72. doi:10.1002/humu.22966

18. Bhattacharyya R, Tan AM, Chan MY, Jamuar SS, Foo R, Iyer P. TCR alphabeta and CD19-depleted haploidentical stem cell transplant with reduced intensity conditioning for Hoyeraal-Hreidarsson syndrome with RTEL1 mutation. Bone Marrow Transplant (2016) 51(5):753-4. doi:10.1038/bmt.2015.352

19. Yamaguchi H, Sakaguchi H, Yoshida K, Yabe M, Yabe H, Okuno Y, et al. Clinical and genetic features of dyskeratosis congenita, cryptic dyskeratosis congenita, and Hoyeraal-Hreidarsson syndrome in Japan. Int J Hematol (2015) 102(5):544-52. doi:10.1007/s12185-015-1861-6

20. Khincha PP, Bertuch AA, Agarwal S, Townsley DM, Young NS, Keel S, et al. Pulmonary arteriovenous malformations: an uncharacterised phenotype of dyskeratosis congenita and related telomere biology disorders. Eur Respir J (2017) 49(1). doi:10.1183/13993003.01640-2016

21. Newton CA, Batra K, Torrealba J, Kozlitina J, Glazer CS, Aravena C, et al. Telomere-related lung fibrosis is diagnostically heterogeneous but uniformly progressive. Eur Respir J (2016) 48(6):1710-20. doi:10.1183/13993003. 00308-2016

22. Kannengiesser C, Borie R, Menard C, Reocreux M, Nitschke P, Gazal S, et al. Heterozygous RTEL1 mutations are associated with familial pulmonary fibrosis. Eur Respir J (2015) 46(2):474-85. doi:10.1183/09031936.00040115

23. Stuart BD, Choi J, Zaidi S, Xing C, Holohan B, Chen R, et al. Exome sequencing links mutations in PARN and RTEL1 with familial pulmonary fibrosis and telomere shortening. Nat Genet (2015) 47(5):512-7. doi:10.1038/ng.3278

24. Barber LJ, Youds JL, Ward JD, McIlwraith MJ, O’Neil NJ, Petalcorin MI, et al. RTEL1 maintains genomic stability by suppressing homologous recombination. Cell (2008) 135(2):261-71. doi:10.1016/j.cell.2008.08.016

25. Uringa EJ, Youds JL, Lisaingo K, Lansdorp PM, Boulton SJ. RTEL1: an essential helicase for telomere maintenance and the regulation of homologous recombination. Nucleic Acids Res (2011) 39(5):1647-55. doi:10.1093/nar/gkq1045

26. Uringa EJ, Lisaingo K, Pickett HA, Brind’Amour J, Rohde JH, Zelensky A, et al. RTEL1 contributes to DNA replication and repair and telomere maintenance. Mol Biol Cell (2012) 23(14):2782-92. doi:10.1091/mbc.E12-03-0179

27. Vannier JB, Pavicic-Kaltenbrunner V, Petalcorin MI, Ding H, Boulton SJ. RTEL1 dismantles T loops and counteracts telomeric G4-DNA to maintain telomere integrity. Cell (2012) 149(4):795-806. doi:10.1016/j.cell.2012.03.030

28. Rudolf J, Makrantoni V, Ingledew WJ, Stark MJ, White MF. The DNA repair helicases XPD and FancJ have essential iron-sulfur domains. Mol Cell (2006) 23(6):801-8. doi:10.1016/j.molcel.2006.07.019

29. Cawthon RM. Telomere measurement by quantitative PCR. Nucleic Acids Res (2002) 30(10):e47. doi:10.1093/nar/30.10.e47

30. Baerlocher GM, Vulto I, de Jong G, Lansdorp PM. Flow cytometry and FISH to measure the average length of telomeres (flow FISH). Nat Protoc (2006) 1(5):2365-76. doi:10.1038/nprot.2006.263

31. Speckmann C, Pannicke U, Wiech E, Schwarz K, Fisch P, Friedrich W, et al. Clinical and immunologic consequences of a somatic reversion in a patient with X-linked severe combined immunodeficiency. Blood (2008) 112(10):4090-7. doi:10.1182/blood-2008-04-153361

32. Fuchs S, Rensing-Ehl A, Speckmann C, Bengsch B, Schmitt-Graeff A, Bondzio I, et al. Antiviral and regulatory $\mathrm{T}$ cell immunity in a patient with stromal interaction molecule 1 deficiency. J Immunol (2012) 188(3):1523-33. doi:10.4049/jimmunol.1102507

33. Maul-Pavicic A, Chiang SC, Rensing-Ehl A, Jessen B, Fauriat C, Wood SM, et al. ORAI1-mediated calcium influx is required for human cytotoxic lymphocyte degranulation and target cell lysis. Proc Natl Acad Sci U S A (2011) 108(8):3324-9. doi:10.1073/pnas.1013285108

34. Pannicke U, Ma Y, Hopfner KP, Niewolik D, Lieber MR, Schwarz K. Functional and biochemical dissection of the structure-specific nuclease ARTEMIS. EMBO J (2004) 23(9):1987-97. doi:10.1038/sj.emboj.7600206

35. Salzer E, Daschkey S, Choo S, Gombert M, Santos-Valente E, Ginzel S, et al. Combined immunodeficiency with life-threatening EBV-associated 
lymphoproliferative disorder in patients lacking functional CD27. Haematologica (2013) 98:473-8. doi:10.3324/haematol.2012.068791

36. Purcell S, Neale B, Todd-Brown K, Thomas L, Ferreira MA, Bender D, et al. PLINK: a tool set for whole-genome association and population-based linkage analyses. Am J Hum Genet (2007) 81(3):559-75. doi:10.1086/519795

37. McKenna A, Hanna M, Banks E, Sivachenko A, Cibulskis K, Kernytsky A, et al. The Genome Analysis Toolkit: a MapReduce framework for analyzing next-generation DNA sequencing data. Genome Res (2010) 20(9):1297-303. doi:10.1101/gr.107524.110

38. DePristo MA, Banks E, Poplin R, Garimella KV, Maguire JR, Hartl C, et al. A framework for variation discovery and genotyping using next-generation DNA sequencing data. Nat Genet (2011) 43(5):491-8. doi:10.1038/ng.806

39. Roy A, Kucukural A, Zhang Y. I-TASSER: a unified platform for automated protein structure and function prediction. Nat Protoc (2010) 5(4):725-38. doi:10.1038/nprot.2010.5

40. Wolski SC, Kuper J, Hanzelmann P, Truglio JJ, Croteau DL, Van Houten B, et al. Crystal structure of the FeS cluster-containing nucleotide excision repair helicase XPD. PLoS Biol (2008) 6(6):e149. doi:10.1371/journal.pbio. 0060149

41. Hirabayashi S, Flotho C, Moetter J, Heuser M, Hasle H, Gruhn B, et al. Spliceosomal gene aberrations are rare, coexist with oncogenic mutations, and are unlikely to exert a driver effect in childhood MDS and JMML. Blood (2012) 119(11):e96-9. doi:10.1182/blood-2011-12-395087

42. Adzhubei IA, Schmidt S, Peshkin L, Ramensky VE, Gerasimova A, Bork P, et al. A method and server for predicting damaging missense mutations. Nat Methods (2010) 7(4):248-9. doi:10.1038/nmeth0410-248

43. Kumar P, Henikoff S, Ng PC. Predicting the effects of coding non-synonymous variants on protein function using the SIFT algorithm. Nat Protoc (2009) 4(7):1073-81. doi:10.1038/nprot.2009.86

44. Kircher M, Witten DM, Jain P, O’Roak BJ, Cooper GM, Shendure J. A general framework for estimating the relative pathogenicity of human genetic variants. Nat Genet (2014) 46(3):310-5. doi:10.1038/ng.2892

45. Lek M, Karczewski KJ, Minikel EV, Samocha KE, Banks E, Fennell T, et al. Analysis of protein-coding genetic variation in 60,706 humans. Nature (2016) 536(7616):285-91. doi:10.1038/nature19057

46. Faure G, Revy P, Schertzer M, Londono-Vallejo A, Callebaut I. The C-terminal extension of human RTEL1, mutated in Hoyeraal-Hreidarsson syndrome, contains Harmonin-N-like domains. Proteins (2014) 82:897-903. doi:10.1002/ prot. 24438

47. Brenchley JM, Karandikar NJ, Betts MR, Ambrozak DR, Hill BJ, Crotty LE, et al. Expression of CD57 defines replicative senescence and antigen-induced apoptotic death of CD8+ T cells. Blood (2003) 101(7):2711-20. doi:10.1182/ blood-2002-07-2103
48. Appay V, van Lier RAW, Sallusto F, Roederer M. Phenotype and function of human T lymphocyte subsets: consensus and issues. Cytometry A (2008) 73(11):975-83. doi:10.1002/cyto.a.20643

49. Wiedemann HP, McGuire J, Dwyer JM, Sabetta J, Gee JB, Smith GJ, et al. Progressive immune failure in dyskeratosis congenita. Report of an adult in whom Pneumocystis carinii and fatal disseminated candidiasis developed. Arch Intern Med (1984) 144(2):397-9. doi:10.1001/archinte.144.2.397

50. Dokal I, Luzzatto L. Dyskeratosis congenita is a chromosomal instability disorder. Leuk Lymphoma (1994) 15(1-2):1-7. doi:10.3109/10428199409051671

51. Ding H, Schertzer M, Wu X, Gertsenstein M, Selig S, Kammori M, et al. Regulation of murine telomere length by Rtel: an essential gene encoding a helicase-like protein. Cell (2004) 117(7):873-86. doi:10.1016/j.cell.2004.05.026

52. Vannier JB, Sandhu S, Petalcorin MI, Wu X, Nabi Z, Ding H, et al. RTEL1 is a replisome-associated helicase that promotes telomere and genome-wide replication. Science (2013) 342(6155):239-42. doi:10.1126/science.1241779

53. Jin T, Wang Y, Li G, Du S, Yang H, Geng T, et al. Analysis of difference of association between polymorphisms in the XRCC5, RPA3 and RTEL1 genes and glioma, astrocytoma and glioblastoma. Am J Cancer Res (2015) 5(7):2294-300.

54. Wynn RF, Cross MA, Hatton C, Will AM, Lashford LS, Dexter TM, et al. Accelerated telomere shortening in young recipients of allogeneic bonemarrow transplants. Lancet (1998) 351(9097):178-81. doi:10.1016/S01406736(97)08256-1

55. Gadalla SM, Sales-Bonfim C, Carreras J, Alter BP, Antin JH, Ayas M, et al. Outcomes of allogeneic hematopoietic cell transplantation in patients with dyskeratosis congenita. Biol Blood Marrow Transplant (2013) 19(8):1238-43. doi:10.1016/j.bbmt.2013.05.021

Conflict of Interest Statement: The authors declare that the research was conducted in the absence of any commercial or financial relationships that could be construed as a potential conflict of interest.

The handling editor declared a past co-authorship with the authors and states that the process nevertheless met the standards of a fair and objective review.

Copyright $\odot 2017$ Speckmann, Sahoo, Rizzi, Hirabayashi, Karow, Serwas, Hoemberg, Damatova, Schindler, Vannier, Boulton, Pannicke, Göhring, Thomay, Verdu-Amoros, Hauch, Woessmann, Escherich, Laack, Rindle, Seidl, Rensing-Ehl, Lausch, Jandrasits, Strahm, Schwarz, Ehl, Niemeyer, Boztug and Wlodarski. This is an open-access article distributed under the terms of the Creative Commons Attribution License (CC BY). The use, distribution or reproduction in other forums is permitted, provided the original author(s) or licensor are credited and that the original publication in this journal is cited, in accordance with accepted academic practice. No use, distribution or reproduction is permitted which does not comply with these terms. 